\title{
Spatial variability of Holocene changes in the annual precipitation pattern: a model-data synthesis for the Asian monsoon region
}

\author{
A. Dallmeyer • M. Claussen • Y. Wang • \\ U. Herzschuh
}

Received: 9 March 2012/Accepted: 27 September 2012/Published online: 23 October 2012

(C) The Author(s) 2012. This article is published with open access at Springerlink.com

\begin{abstract}
This study provides a detailed analysis of the mid-Holocene to present-day precipitation change in the Asian monsoon region. We compare for the first time results of high resolution climate model simulations with a standardised set of mid-Holocene moisture reconstructions. Changes in the simulated summer monsoon characteristics (onset, withdrawal, length and associated rainfall) and the mechanisms causing the Holocene precipitation changes are investigated. According to the model, most parts of the Indian subcontinent received more precipitation (up to $5 \mathrm{~mm} /$ day) at mid-Holocene than at present-day. This is related to a stronger Indian summer monsoon accompanied by an intensified vertically integrated moisture flux convergence. The East Asian monsoon region exhibits local inhomogeneities in the simulated annual precipitation signal. The sign of this signal depends on the balance of decreased pre-monsoon and increased monsoon precipitation at mid-Holocene compared to present-day. Hence, rainfall changes in the East Asian monsoon domain are
\end{abstract}

\footnotetext{
A. Dallmeyer $(\bowtie) \cdot$ M. Claussen

Max Planck Institute for Meteorology, Bundesstrasse 53, 20146 Hamburg, Germany

e-mail: anne.dallmeyer@zmaw.de

M. Claussen

Meteorological Institute, University of Hamburg,

Bundesstrasse 55, 20146 Hamburg, Germany

Y. Wang · U. Herzschuh

Alfred Wegener Institute for Polar and Marine Research,

Telegrafenberg A43, 14473 Potsdam, Germany

Y. Wang · U. Herzschuh

Institute of Earth and Environmental Science,

University of Potsdam, Karl-Liebknecht-Strasse 24-25,

14476 Potsdam, Germany
}

not solely associated with modifications in the summer monsoon circulation but also depend on changes in the mid-latitudinal westerly wind system that dominates the circulation during the pre-monsoon season. The proxybased climate reconstructions confirm the regional dissimilarities in the annual precipitation signal and agree well with the model results. Our results highlight the importance of including the pre-monsoon season in climate studies of the Asian monsoon system and point out the complex response of this system to the Holocene insolation forcing. The comparison with a coarse climate model simulation reveals that this complex response can only be resolved in high resolution simulations.

Keywords Asian monsoon - Holocene - Precipitation · Climate modelling $\cdot$ Moisture reconstructions

\section{Introduction}

Monsoon systems primarily form due to seasonal and latitudinal differences in the incoming solar radiation. The different heat capacities of the continent and ocean lead to strong land-sea thermal contrasts (Webster et al. 1998). As consequence, large-scale pressure gradients are generated inducing strong low-level atmospheric wind circulations that reverse seasonally according to the change in insolation. The strength of the monsoonal circulation is susceptible to variations in all components of the climate system i.e. of those on land, in the atmosphere and in the oceans. Monsoon systems are therefore characterised by a strong temporal variability covering multi-millennial to intraseasonal timescales (e.g. Lau et al. 2000; Wang 2006; Ding 2007).

The Asian monsoon system is the strongest monsoon system of the world (Clift and Plumb 2008). It incorporates 
the East Asian and the Indian monsoon, which are independent sub-systems showing different characteristics and variability, but also strongly interact (Wang et al. 2001; Ding and Chan 2005). These differences are at least partly related to the different land-ocean configurations (including topography) in the sub-monsoon domains (Wang et al. 2003)

The Indian summer monsoon is characterised by the meridional pressure-gradient between the monsoon trough in North India and the Mascarene high causing an interhemispheric circulation (Wang et al. 2003; Wang 2006). The strength of this circulation and the onset and maintenance of the Indian summer monsoon are to a large part determined by climate processes on the Tibetan Plateau that forms an elevated heat source for the atmosphere in late spring and summer and enhances the thermal contrast between the land and ocean in the Indian monsoon sector (e.g. Ye and $\mathrm{Wu}$ 1998; Wu et al. 2007). The seasonal March of the Indian monsoon rainband is strongly connected with the movement of the Intertropical Convergence Zone (ITCZ) and reaches its northernmost position in midJuly (Wang et al. 2003). More than $80 \%$ of the annual precipitation in the Indian subcontinent originates from the summer monsoon (Wang et al. 2001). Rainfall peaks early in summer (June-July, Wang et al. 2003).

In contrast, the East Asian summer monsoon is controlled by the zonal pressure-gradient between the monsoon trough on the Asian continent and the western Pacific subtropical high (Webster et al. 1998). As a result of the east-west thermal contrast, a planetary subtropical front is formed (Meiyu-Baiu frontal system) whose seasonal March determines the propagation of the East Asian summer monsoon rainbelt (e.g. Ding 2007). The subtropical front reaches the northernmost position during early July and is separated from the ITCZ, which forms a second rainband in East Asia (tropical rainbelt) affecting mainly the western North Pacific monsoon. Rainfall associated with the ITCZ over the East Asian sector peaks during August and only affects the area south of $25^{\circ} \mathrm{N}$ (Wang et al. 2003). The interplay of the mid-latitude westerlies, the subtropical circulation around the western Pacific subtropical high and the tropical circulation including the Indian monsoon flow makes the East Asian monsoon domain unique and enables the occurrence of many significant weather and climate phenomena (Ding 2007). In contrast to other monsoon regions, the precipitation in large parts of the East Asian monsoon domain is not temporally confined to the summer monsoon season. According to Yihui and Zunya (2008), spring precipitation accounts for approximately $32 \%$ of the annual total in the middle and lower reaches of the Yangtze River $\left(110-122^{\circ} \mathrm{E}, 28-32^{\circ} \mathrm{N}\right)$ and is also very dominant in the Huaxi region $\left(100-110^{\circ} \mathrm{E}, 30-35^{\circ} \mathrm{N}\right)$. In South China $\left(110-122^{\circ} \mathrm{E}, 20-28^{\circ} \mathrm{N}\right)$, spring and summer precipitation contribute to the annual total in equal parts (35 and $38 \%$, respectively). However, precipitation in North $\left(115-125^{\circ} \mathrm{E}, 35-42^{\circ} \mathrm{N}\right)$ and North East China $\left(122-135^{\circ} \mathrm{E}, 40-52^{\circ} \mathrm{N}\right)$ clearly peaks in summer as expected for monsoon regions.

At mid-Holocene, differences in the Earth's orbital configuration compared to present-day lead to differences in the incoming solar radiation (Berger 1978). During summer (winter), the insolation was increased (decreased) by approx. $5 \%$ on the Northern Hemisphere yielding an enhancement of the seasonal cycle. Climate modelling studies suggest a general strengthening of the Asian summer monsoon circulation as response to this insolation forcing that can mainly be explained by an intensification of the land-sea thermal gradient (e.g. Braconnot et al. 2007a, 2008; Marzin and Braconnot 2009; Wang et al. 2010a). Precipitation is assumed to be increased in most parts of the continental monsoon domain during the midHolocene, but the analysis is often confined to the summer season (June-August, e.g. Wang et al. 2010a) which may neither portray the entire summer monsoon season nor the annual mean precipitation in this region.

Feedbacks in the climate system such as interactions of the atmosphere and the ocean or the vegetation have been shown to modify the initial response to the insolation forcing. The strength of these interactions reveals regional dissimilarities in the Asian monsoon domain as well as contradictory contributions to the Holocene climate change in different climate models (see Dallmeyer et al. 2010 and references therein). To assess the performance of the different models, the model results have to be validated to paleoclimate reconstructions.

Climate reconstructions confirm the increase in precipitation in most regions of the Asian monsoon domain during early and mid-Holocene (e.g. Fleitmann et al. 2003; Wang et al. 2005; Herzschuh et al. 2006; Prasad and Enzel 2006) and suggest differences in the precipitation response to the insolation forcing between the Indian and East Asian monsoon region (An et al. 2000; Maher and $\mathrm{Hu}$ 2006; Maher 2008). However, most of the proxies do not resolve seasonal signals but rather record an aggregated annual signal. Therefore, the proxies cannot a priori provide information on seasonal climate phenomena such as the summer monsoons. For example, the precipitation signal in vegetation-proxies is smoothed by the soil moisture storage capacity. Lake water level proxies from closed lakes record the total accumulated precipitation relative to evaporation. However, by analogy to the present summer precipitation dominance these proxy-records have often served as proof for the simulated intensification of the Asian summer monsoon. So far, the reconstructions have lacked a consistent age control and revealed large disparities in the sample resolution that might have influenced the 
interpretation of these records and their applicability in comparative studies of climate modelling results and reconstructions. Recently, Wang et al. (2010b) have provided a synthetic review of the spatial and temporal pattern of moisture evolution in monsoonal central Asia that is based on more than 90 synchronised proxy records.

In this study, we compare results of high-resolution global climate model simulations with these synchronised reconstructions for the mid-Holocene time-slice. Using the climate model results, we (1) quantify changes in the summer monsoon characteristic between the mid-Holocene and present-day, (2) investigate how seasonal precipitation changes affect the simulated annual precipitation signal, (3) identify atmospheric mechanisms leading to the reconstructed spatial moisture pattern and (4) analyse the processes causing the differences in the precipitation response between the Indian and East Asian monsoon region. With this study, we provide for the first time a comprehensive and consistent comparison of reconstructions and climate model results for the mid-Holocene Asian monsoon climate.

\section{Methods}

\subsection{Model setup and experiments}

To analyse differences in climate between the mid-Holocene $(6,000$ years before present, referred to as $6 \mathrm{k})$ and present-day $(0 \mathrm{k})$, we performed time-slice experiments with the model ECHAM5/JSBACH. This model consists of the general circulation model for the atmosphere ECHAM5 (Roeckner et al. 2003) and the land surface scheme JSBACH (Raddatz et al. 2007) that also included a dynamic vegetation module in our simulations (Brovkin et al. 2009). The models ran with the spectral resolution T106L31. This corresponds to a longitudinal distance of approx. $1.125^{\circ}$ and 31 levels in the vertical.

At mid-Holocene, the eccentricity of the Earth's orbit was slightly higher than today, the tilt of the Earth's axis was stronger by approximately $0.7^{\circ}$ and the Earth reached perihelion in September instead of January (Berger 1978). These differences in the orbital parameters led to seasonal and latitudinal differences in the incoming solar radiation at the top of the atmosphere, i.e. the insolation (Fig. 1). Mid-Holocene insolation was increase during summer and early autumn in the Northern Hemisphere and decreased during winter and early spring leading to an enhancement of the seasonal cycle compared to present-day. In the Tropics, the maximum positive insolation change occurred in August, i.e. during the monsoon season (Fig. 1).

In this study, we conducted two experiments, one with mid-Holocene orbital configuration $\left(\mathrm{AV}_{6 \mathrm{k}}\right)$, one with
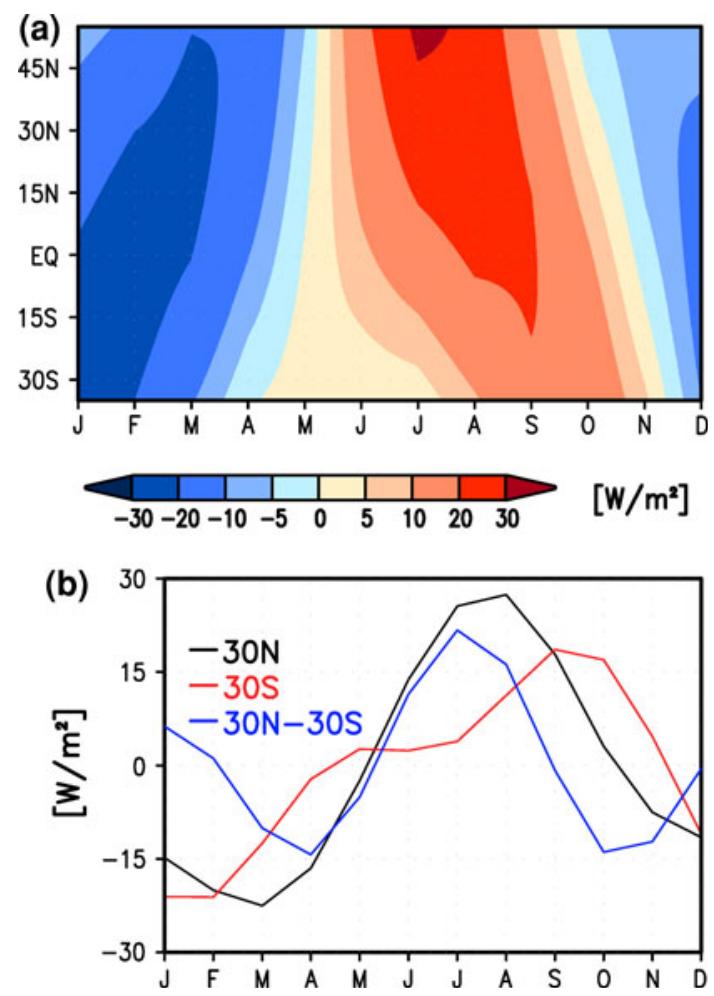

Fig. 1 Insolation difference between mid-Holocene (6k) and presentday $(0 \mathrm{k})$ in $\mathrm{W} / \mathrm{m}^{2}$; a zonal mean change per month in the model; b insolation change per month at $30^{\circ} \mathrm{N}$ (black) and $30^{\circ} \mathrm{S}$ (red) and change in the gradient $30^{\circ} \mathrm{N}-30^{\circ} \mathrm{S}$. Shifts in calendar are not accounted for, i.e. the model calendar is used

present-day orbital configuration $\left(\mathrm{AV}_{\mathrm{Ok}}\right)$ prescribed. In $A V_{6 k}$ and $A V_{0 k}$, monthly mean sea surface temperature and sea-ice distribution were prescribed according to their mid-Holocene and pre-industrial distributions, respectively. To account for interannual variability, these values were taken from 120 years of a coarse resolution simulation. This simulation has been performed with the comprehensive Earth system model ECHAM5/JSBACHMPIOM (Fischer and Jungclaus 2011), which included the general circulation model for the ocean MPIOM (Marsland et al. 2003).

During both simulations, atmospheric composition was fixed at pre-industrial values, i.e. $\mathrm{CO}_{2}$-concentration was set to $280 \mathrm{ppm}$. ECHAM5/JSBACH had been brought to quasiequilibrium climate state (spin-up of approx. 200 years) before it ran for additional 30 years (analysis period). All results and plots are based on these 30 years of analysis period.

The model results have been tested against climate observations and reanalysis data to prove that the model captures the major structure of the present-day global and regional climate. Present-day annual and seasonal precipitation maps as well as a discussion of the major precipitation differences to observational datasets are provided in the "Appendix". 
2.2 Calculation of the monsoon onset and withdrawal period

Past moisture changes inferred from proxy studies in eastern and southern Asia were hitherto generally assumed to originate almost exclusively from changes in the summer monsoon as this circulation pattern is responsible for most of the present-day annual precipitation in these areas; also paleoclimate modelling studies focus often on the summer season (e.g. Wei and Wang 2004; Li et al. 2009; Wang et al. 2010a; Zhou and Zhao 2010). For the purpose of simplification, the summer monsoon season is usually represented by climate means of the months June to August or September and not explicitly calculated in paleoclimate studies. We are not aware of previous modelling studies assessing changes in the summer monsoon onset, withdrawal, length and related precipitation between the midHolocene and present-day in detail for the entire Asian monsoon region.

Following the definition of Wang and LinHo (2002), we calculate the changes in these monsoon season characteristics based on the simulated relative pentad mean rainfall rate $\left(\mathrm{rp}_{\mathrm{i}}\right)$ defined as difference between the pentad mean rainfall rate $\left(\mathrm{p}_{\mathrm{i}}\right)$ and the January mean rainfall rate $\left(\mathrm{p}_{\mathrm{jan}}\right)$ :

$\mathrm{rp}_{\mathrm{i}}=\mathrm{p}_{\mathrm{i}}-\mathrm{p}_{\mathrm{jan}} \quad \mathrm{i}=1,2, \ldots, 73$

The period in which $\mathrm{rp}_{\mathrm{i}}$ reaches values above $5 \mathrm{~mm} /$ day represents the monsoon season. Accordingly, the onset (withdrawal) is defined as the pentad in which $\mathrm{rp}_{\mathrm{i}}$ exceeds (falls below) $5 \mathrm{~mm} /$ day. This method is a good approximation of the observed present-day monsoon propagation.

\subsection{Reconstructions-based moisture index}

The moisture signal from the previously published records (mostly based on lake sediment analyses) were transferred into a three-scale moisture index categorising the midHolocene climate as 'wetter than', 'similar as', or 'drier than' at present-day. Generally, the moisture indices are relative, in a semi-quantitative sense for each individual case and therefore can only be compared qualitatively to the model results. For detailed information concerning the methods and original results for most sites we refer to Wang et al. (2010b). Meanwhile, during producing the moisture index, we are aware of the following potential uncertainties:

Chronology: We attempted to construct comparable agedepth models among the records based on consistent calibration methods. However, the potentially varying dating uncertainties, especially the so-called "carbon reservoir effect" for the lacustrine records still need to be considered with cautions.
Various moisture indicators: We drew the moisture information from various proxies (e.g. pollen, ostracods, stable isotope measurements, element ratios), with different indications for the moisture changes, e.g. reconstructed precipitation, lake level changes, moisture balance changes and even the qualitative descriptions on the dry/wet conditions, leading to the potentially different responses to the real climate changes.

Seasonal variations in moisture: Considering the rough information deduced from the proxy data, it is impossible to acquire the seasonal variations, limiting the comparability of the index and the modelling results (Wang et al. 2010b). Even more problematic, the single proxies may represent moisture signals of different seasons of the year and most proxies integrate over a certain or even varying period of the year e.g. lake level proxies or vegetation proxies.

\section{Results}

3.1 Comparison of the simulated annual precipitation pattern with proxy-based moisture reconstructions

Figure 2 shows the significant annual mean precipitation difference between the mid-Holocene (6k) and the presentday simulation (0k). Most of the continental Asian monsoon region experiences a wetter climate during midHolocene. Precipitation is increased by up to $0.7 \mathrm{~mm} /$ day in North East China and North India, up to $1 \mathrm{~mm} /$ day in South China and up to $3 \mathrm{~mm} /$ day at the Himalaya mountain range. Precipitation is decreased in southern Indochina (up to $0.6 \mathrm{~mm} / \mathrm{day}$ ), on the south-eastern Tibetan Plateau (up to

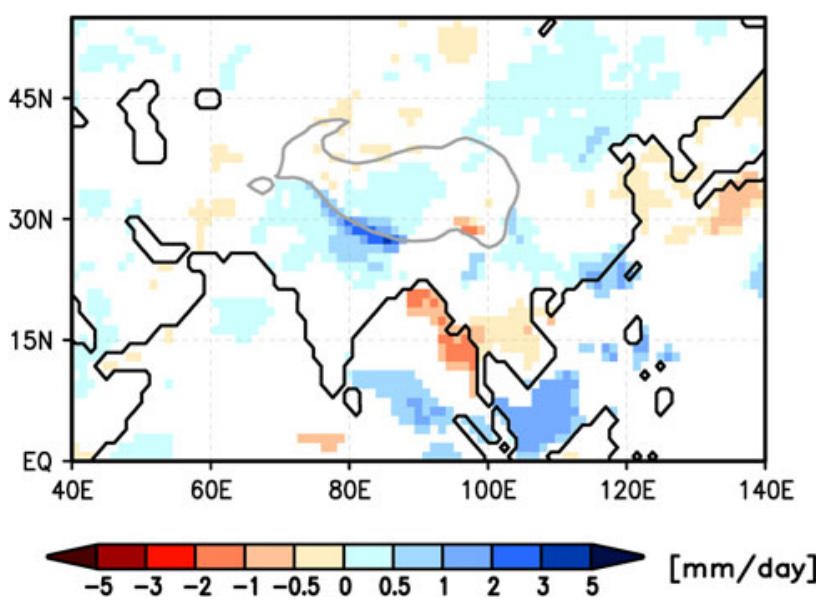

Fig. 2 Significant ( $T$ test, $90 \%$ ) difference in annual mean precipitation ( $\mathrm{mm} /$ day) between the mid-Holocene $(6 \mathrm{k})$ and the present-day (0k) simulation, based on the 30 years of analysis period. The grey line marks the Tibetan Plateau that is here defined as the region where the orography in the model exceeds $2,500 \mathrm{~m}$ 
$1 \mathrm{~mm} /$ day) and in the Yangtze-Huanghe-Plain (up to $0.4 \mathrm{~mm} /$ day). Figure 3 shows the reconstructed moisture index (Wang et al. 2010b) in comparison with the simulated relative precipitation difference between mid-Holocene and present-day. Overall, the model and reconstructions show qualitatively a similar pattern of moisture change with wetter conditions in North India and large parts of the Tibetan Plateau as well as in south-western China. In north-western China, the model and reconstructions suggest drier or similar conditions during mid-Holocene. In the East Asian monsoon region, they partly disagree, particularly in Central China. The model calculates less annual mean precipitation in a broad region between ca. $25-35^{\circ} \mathrm{N}$ and $95-120^{\circ} \mathrm{E}$ at $6 \mathrm{k}$. This signal is mostly not significant on a $90 \%$ significance level (cf. Fig. 2), which reveals a high interannual variability in the model. The reconstructions suggest predominantly a wetter climate in Central China during mid-Holocene, but even the reconstructions from proxy records are rather contradictory from site to site, which may be caused by topographical differences or local hydrological processes.

\subsection{Simulated change in summer monsoon season characteristics}

Following the monsoon season definition of Wang and LinHo (2002), we assess if the difference in summer monsoon precipitation is responsible for the difference in the annual total between the mid-Holocene (6k) and the present-day (0k) simulation.

Due to the reduced solar radiation on the Northern Hemisphere during spring (Fig. 1) and the accompanied weaker temperature gradient between ocean and land in the

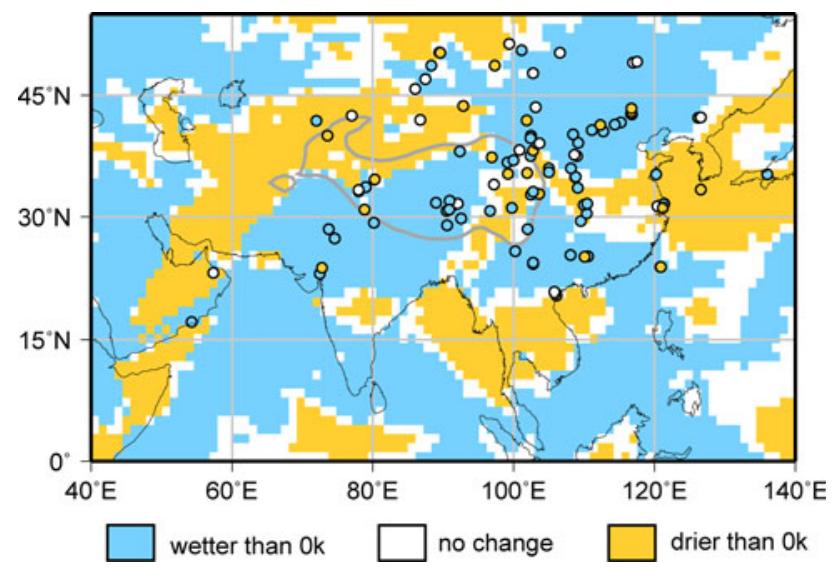

Fig. 3 Reconstructed semi-quantitative moisture difference between the mid-Holocene and present-day (dots) based on Wang et al. (2010b) and simulated relative annual mean precipitation difference (6-0k/0k, shaded) between mid-Holocene and present-day, adapted to the three-scale moisture reconstructions. Please notice, that in contrast to Fig. 2 also less significant values are shown. Grey line marks the Tibetan Plateau pre-monsoon season, the summer monsoon starts approx. 2-8 pentads later at $6 \mathrm{k}$ than at $0 \mathrm{k}$ (Fig. $4 \mathrm{a}$ ). Only at the margin area of the present-day monsoon domain and in Northeast China, the monsoon season begins approx. 2-4 pentads earlier in the mid-Holocene simulation than at present-day. This probably indicates a faster advance of the summer monsoon into the continental interior at $6 \mathrm{k} \mathrm{com-}$ pared to $0 \mathrm{k}$ as the time interval between the monsoon onset in the south and the monsoon onset in the north is shorter at $6 \mathrm{k}$ than at $0 \mathrm{k}$. The withdrawal of the summer monsoon is postponed by 0.5 pentads in South India and Indochina to up to 10 pentads in East China and begins earlier at the Bay of Bengal and the South China Sea (approx. 4-6 pentads, Fig. 4b). This also indicates a faster retreat of the summer monsoon.

Related to the shifts in the onset and withdrawal period, the summer monsoon season length is different at $6 \mathrm{k}$ and at 0k (Fig. 4c). In large parts of the continent, the monsoon season is prolonged by up to 10 pentads and the monsoon related precipitation is enhanced during the mid-Holocene. Exceptions are parts of Middle and North East India, Indochina and Bangladesh which experience a shorter monsoon season by approx. 2-8 pentads and less monsoonal precipitation in $6 \mathrm{k}$. These are approximately also the areas showing much less annual mean precipitation in the mid-Holocene simulation than in the present-day one, but changes in summer monsoon precipitation cannot fully explain the simulated annual mean precipitation signal (Fig. 2), particularly in the East Asian monsoon region (e.g. Central Eastern China).

To further analyse the differences in the precipitation pattern between mid-Holocene and present-day, Hovmöller diagrams are provided (Fig. 5) showing the latitudinal structure of the seasonal precipitation cycle in an East Asian (110-120 $\left.{ }^{\circ} \mathrm{E}\right)$ and Indian monsoon sector $\left(70-80^{\circ} \mathrm{E}\right)$. These diagrams reveal a similar picture as Fig. 4: Central Eastern China (approx. $20-35^{\circ} \mathrm{N}$ ) receives less spring precipitation during mid-Holocene. In summer, the major East Asian summer monsoon rainband is slightly shifted northward. Therefore, precipitation is decreased in the region between 5 and $20^{\circ} \mathrm{N}$ and increased north of it. During autumn, East Asian monsoon precipitation is enhanced at $6 \mathrm{k}$ compared to $0 \mathrm{k}$. The Indian summer monsoon onset is postponed providing less precipitation north of the Equator during May and June. The major summer rainband is slightly shifted northward which leads to an increase of summer precipitation at ca. $30^{\circ} \mathrm{N}$. In the post-monsoon season, the Indian continent experiences more precipitation during mid-Holocene.

Please notice that we performed the seasonal analysis based on the modern calendar. Due to the precession, the starting date and length of the seasons change in time (cf. Joussaume and Braconnot 1997). Taking astronomical 

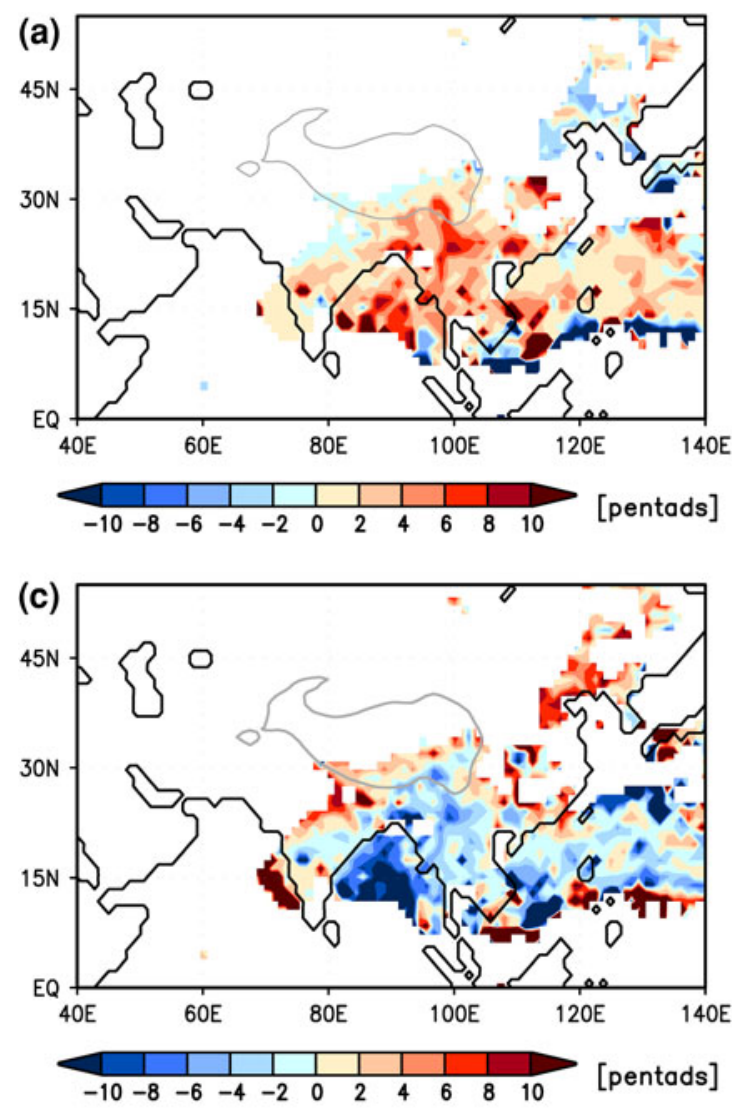

Fig. 4 Simulated difference in a onset pentad, $\mathbf{b}$ withdrawal pentad, c length of the Asian summer monsoon season (pentads) as well as d differences in monsoon related precipitation $(\mathrm{mm})$ between midHolocene (6k) and present-day (0k), calculated following Wang and LinHo (2002). White shaded regions are areas in which the criteria of

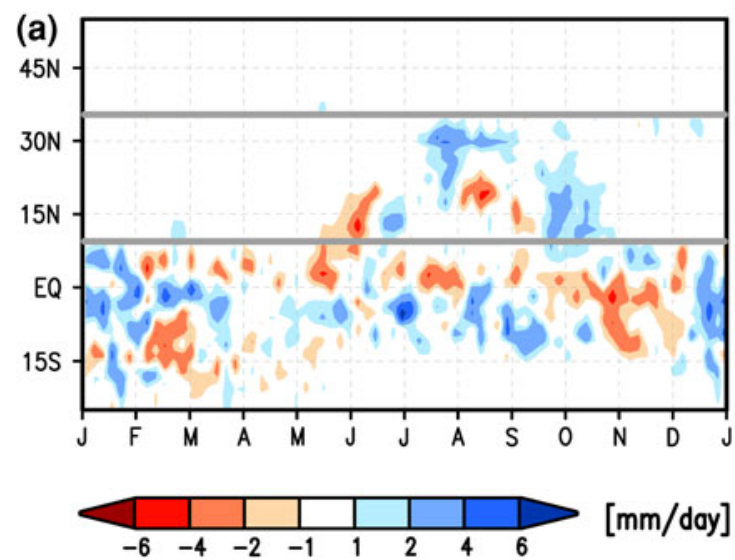

Fig. 5 Hovmöller diagram of pentad mean precipitation differences between the mid-Holocene and present-day ( $\mathrm{mm} /$ day) for $\mathbf{a}$ an Indian monsoon sector $\left(70-80^{\circ} \mathrm{E}\right)$ and $\mathbf{b}$ an East Asian monsoon sector $\left(110-120^{\circ} \mathrm{E}\right)$. The section separated by grey lines indicates the

fixed-points (equinoxes and solstice) as definition of the seasons, the summer season, for instance, is shorter by 4 days and the autumn season starts earlier at
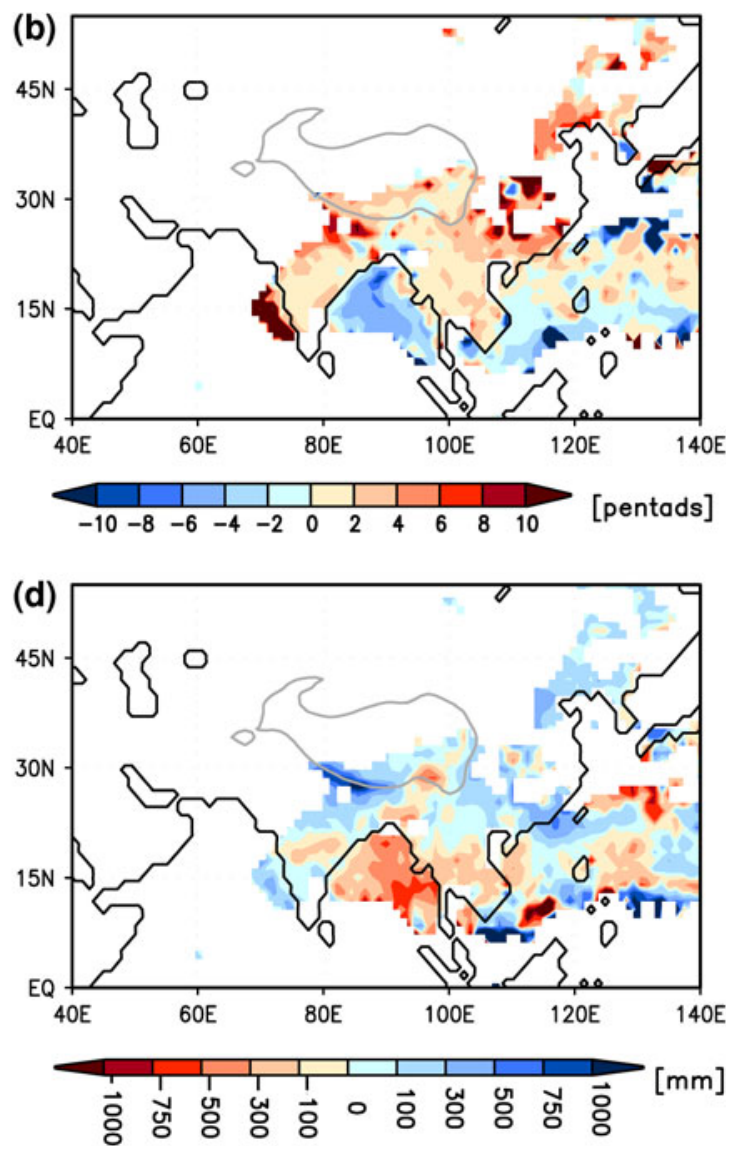

a relative mean rainfall rate above $5 \mathrm{~mm} /$ day is not fulfilled in either the mid-Holocene or the present-day simulation, i.e. areas outside the monsoon region. The grey line marks the Tibetan Plateau. For a significance test of the seasonal precipitation changes, please see Fig. 7

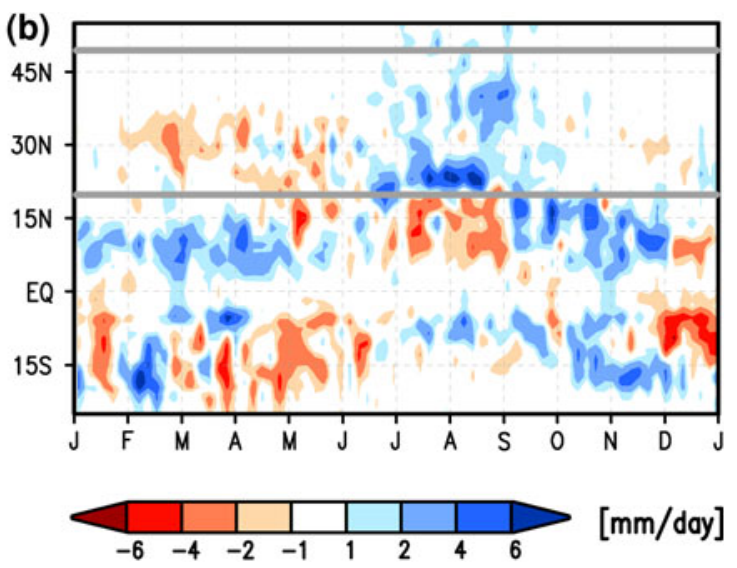

monsoon domain on the Asian continent, i.e. India and East China, respectively. For a significance-test of the seasonal precipitation changes, please see Fig. 7

mid-Holocene compared to present-day. As we discuss the annual precipitation cycle in its entirety, the shift in calendar should not affect the conclusions drawn in this study. 
Fig. 6 Annual cycle of precipitation $(\mathrm{mm} / \mathrm{day})$ in the mid-Holocene (blue) and present-day simulation (black) as well as the difference in the annual precipitation cycle between both simulations ( $\mathrm{red}$ ) for different regions in the Asian monsoon domain. These regions are indicated in $\mathbf{a}$, which is a combined figure of Figs. 2 and 3 showing the reconstructed moisture (dots) and simulated precipitation (shaded) difference between midHolocene and present-day. Less significant differences are displayed in weaker colours.

North-western China and Mongolia are outside the monsoon region and therefore not further discussed. For a significance test of the seasonal precipitation changes, please see Fig. 7
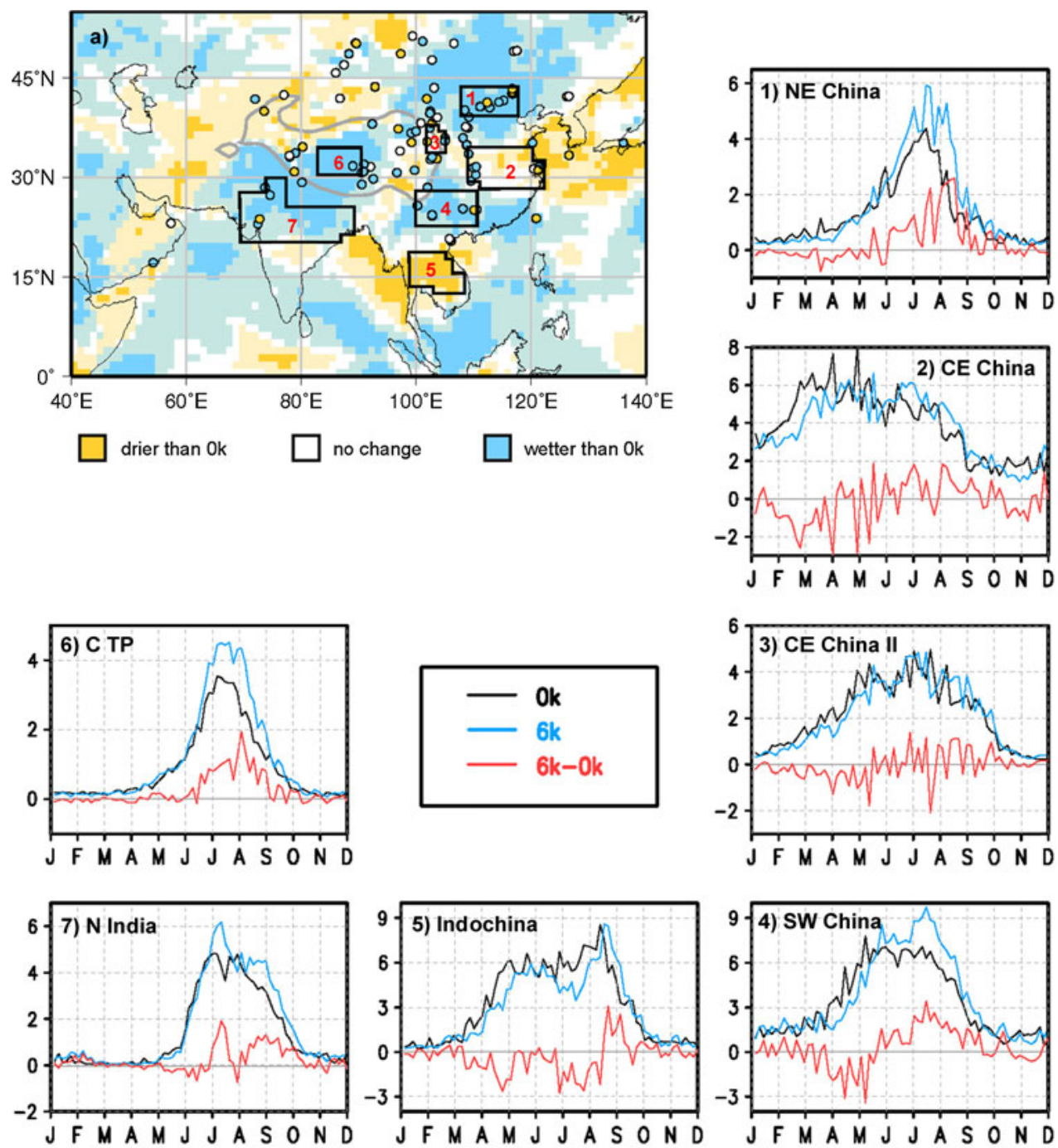

\section{Discussion}

4.1 Insolation differences and regional modes of seasonal precipitation

Generally, the reconstructions and the model results show a rather chessboard like, patchy and non-systematic moisture change in the Asian monsoon region. This patchiness underlines the complexity of the Asian monsoon system and it exposes the complexity of the response of this system to the Holocene insolation change revealing differences in the individual sub-regions of the Asian monsoon domain. The cause of this different behaviour can probably be found in the different nature of the monsoon systems. The Indian monsoon is determined by meridional temperature and pressure gradients. Therefore the Holocene insolation change, which is zonally uniform but reveals meridional variations, has a different effect on the Indian monsoon than on the East Asian monsoon that is formed by zonal temperature and pressure gradients. In the Indian monsoon region, not only the incoming solar radiation but also the meridional insolation gradient (and therewith the energy gradient) is enhanced during summer and reduced during the other seasons (cf. Fig. 1). In the East Asian monsoon domain, the incoming solar radiation is enhanced during mid-Holocene summer and reduced in the other seasons, but the modification of the zonal pressure gradient is only related to the different response of the ocean and the continent to the insolation forcing due to their different heat capacities. Therefore, the Indian and East Asian monsoon systems are suggested to respond differently to the Holocene insolation forcing with respect to their dynamical change in the different seasons.

The good (qualitative) resemblance of the model results and reconstructions allows us to assess the mechanism leading to the reconstructed moisture change and can help to understand the patchy signal in the reconstructions. In Sect. 3.2 we have already pointed out that the change in monsoon related precipitation between the mid-Holocene and the present-day simulations cannot fully explain the 

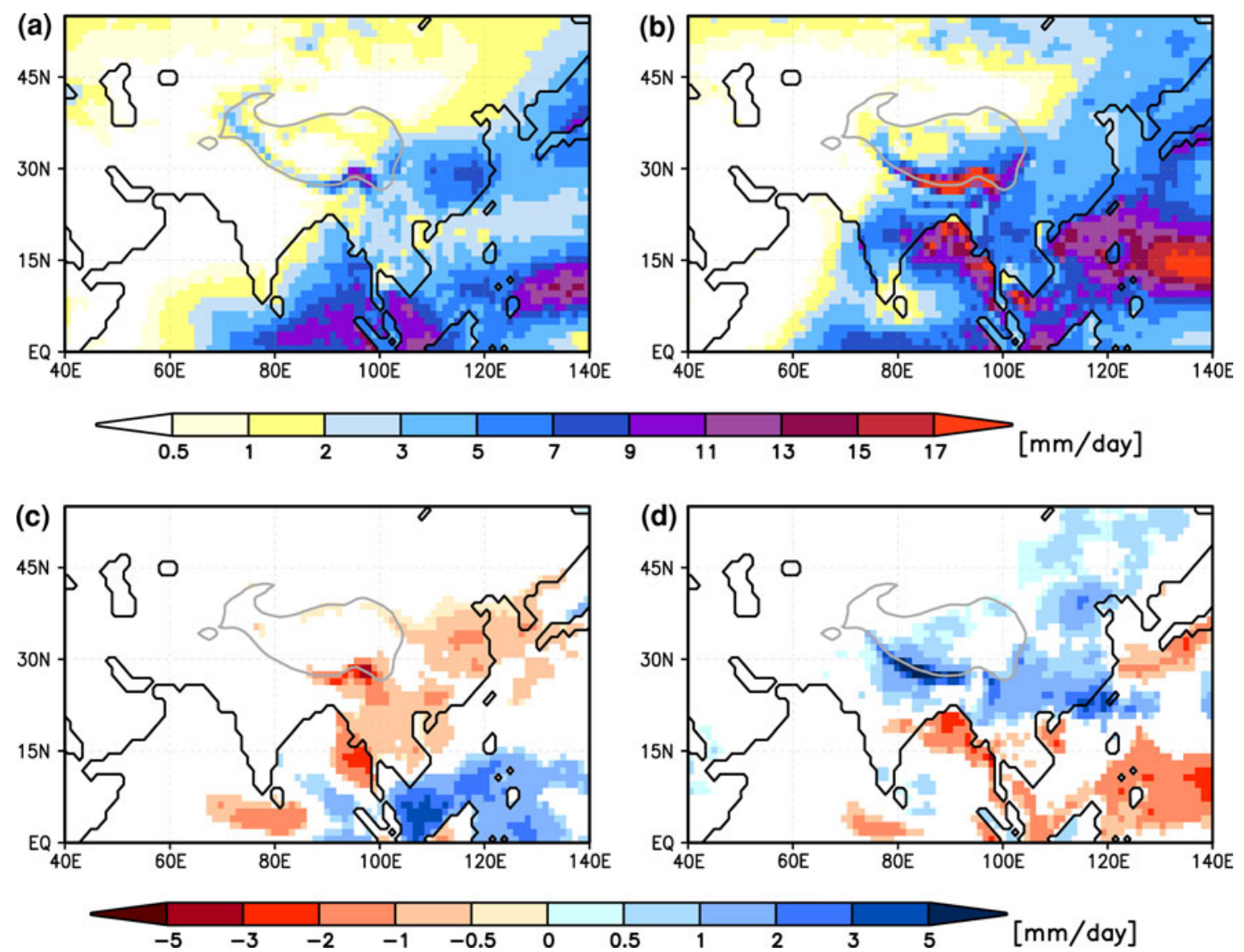

Fig. 7 Simulated precipitation ( $\mathrm{mm} /$ day) averaged over a the present-day spring season (February-May) and $\mathbf{b}$ idealised summer monsoon season (June-September), upper panel present-day

change in annual total. The insolation forcing also affects precipitation in other seasons (cf. Fig. 5). To further investigate the Holocene moisture change, we look at the simulated seasonal precipitation cycle in different areas of Asia representing zones with a characteristic mid-Holocene to present-day annual precipitation signal in the model (Fig. 6). These regions are defined (numbers) and marked (polygons) in Fig. 6a.

The difference in the seasonal cycle between midHolocene (6k) and present-day (0k) confirms that in some regions the change in annual mean precipitation is not fully determined by the change in summer monsoon rainfall. Within the Asian monsoon region, three different modes in the precipitation signal can be identified compared to present-day:

I decreased mid-Holocene precipitation in spring and increased mid-Holocene in summer (e.g. NE China, CE China, SW China; these are all areas located in the East Asian monsoon region)

II increased mid-Holocene precipitation during summer (e.g. N India, CTP; these are areas located in the Indian monsoon region) distribution, lower panel significant ( $T$ test, $90 \%$ ) difference between mid-Holocene and present-day. The grey line marks the Tibetan Plateau

III decreased mid-Holocene precipitation in spring and summer (e.g. Indochina; this is an area in the transition zone of both monsoons)

The annual mean precipitation change in all considered areas is, thus, mostly determined by the sum of precipitation changes in spring and summer. In the following, mechanisms leading to the precipitation change in these two seasons are investigated in more detail.

\subsection{Mechanisms causing differences in the simulated spring precipitation}

Figure 7 displays the spatial precipitation distribution averaged over the spring season (here defined as months February to May, FMAM) and monsoon season (here defined as month June to September). Compared to other parts of the continental monsoon regions, Southeast Asia (e.g. Indochina, Central and south-western China) receives already a large amount of precipitation during the spring season. In central-eastern and South China, the simulated mean precipitation rates in FMAM reach values of up to $8 \mathrm{~mm} /$ day and even exceed the precipitation rates during 

a upper-tropospheric zonal wind in $200 \mathrm{hPa}(\mathrm{m} / \mathrm{s})$; b vertical $\mathrm{Pa} / \mathrm{s}$ ), (uplift: red, sinking: blue); c vertically integrated moisture flux [vector, $(\mathrm{kg} / \mathrm{ms})$ ] and its convergence [shaded, $\left(10 \times 10^{-5} \mathrm{~kg} / \mathrm{m}^{2} \mathrm{~s}\right)$ convergence $=$ blue (moisture sink), divergence $=$ red (moisture source)] as well as d near surface air temperature [shaded, $\left.\left({ }^{\circ} \mathrm{C}\right)\right]$ and mean sea level pressure [contours, $(\mathrm{hPa})$ ], averaged over the spring season (February-May) The grey line
Fig. 8 Simulated present-day velocity in $400 \mathrm{hPa}(-0.01$ marks the Tibetan Plateau
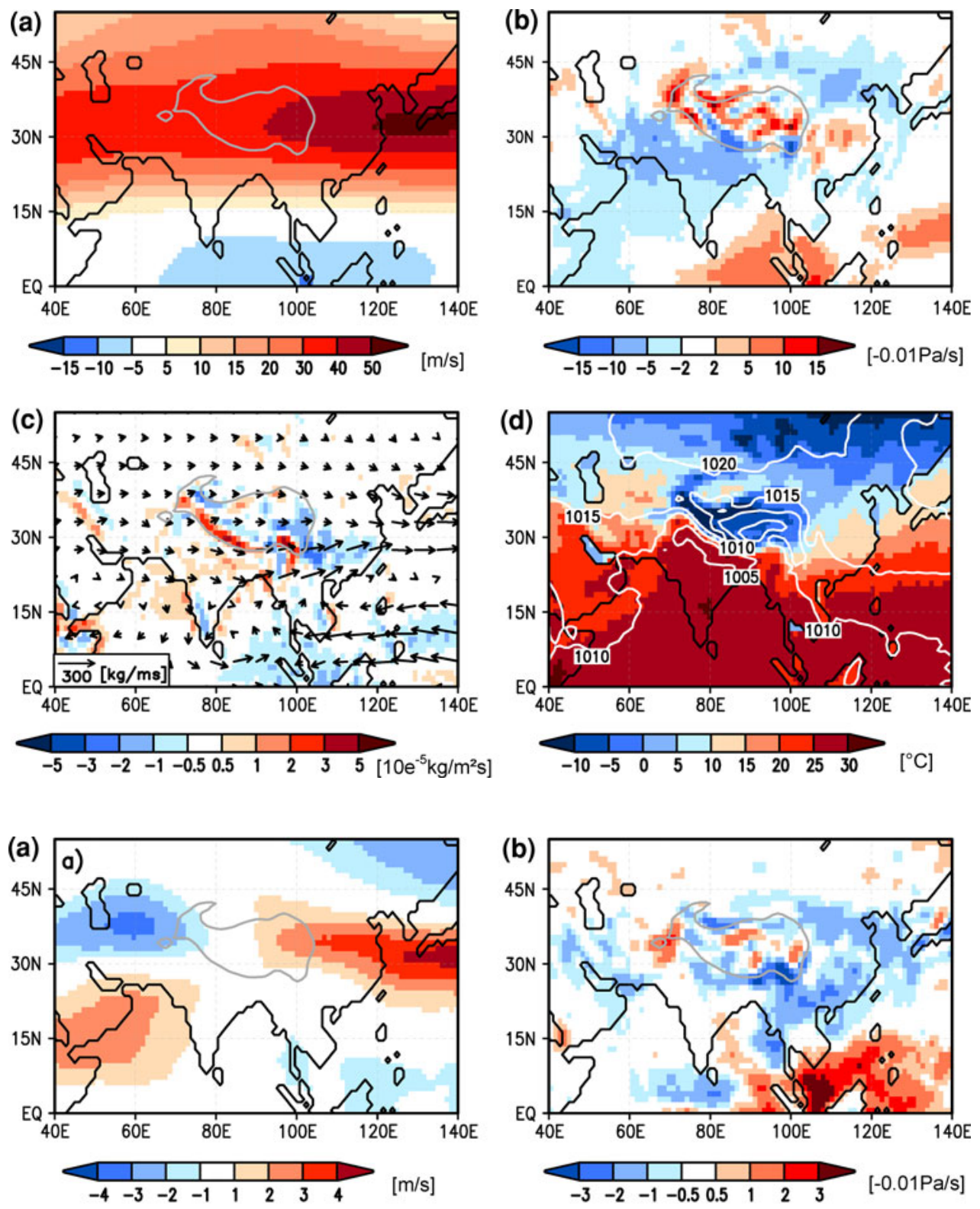

Fig. 9 Same as Fig. 8, bu difference between midHolocene and present-day, averaged over the spring season (February-May); a uppertropospheric zonal wind in $200 \mathrm{hPa}(\mathrm{m} / \mathrm{s})$; b vertical velocity in $400 \mathrm{hPa}(-0.01$ $\mathrm{Pa} / \mathrm{s})$; c vertically integrated moisture flux [vector, $(\mathrm{kg} / \mathrm{ms})$ ] and its convergence [shaded, $\left.\left(10 \times 10^{-5} \mathrm{~kg} / \mathrm{m}^{2} \mathrm{~s}\right)\right] ;$ d near surface air temperature [shaded, $\left.\left({ }^{\circ} \mathrm{C}\right)\right]$ and mean sea level pressure [contours, $(\mathrm{hPa})]$

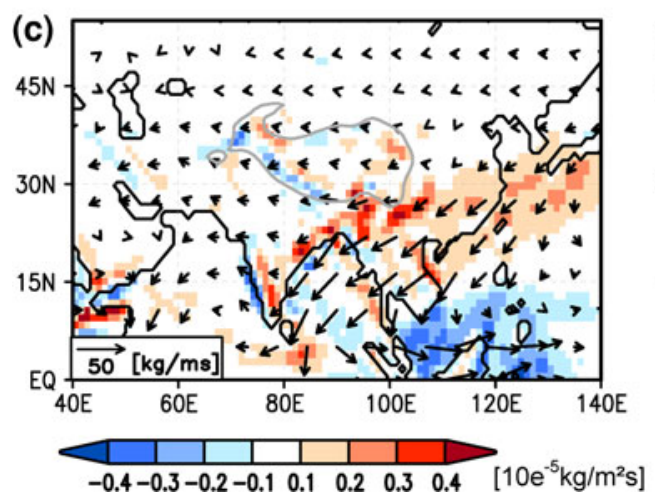

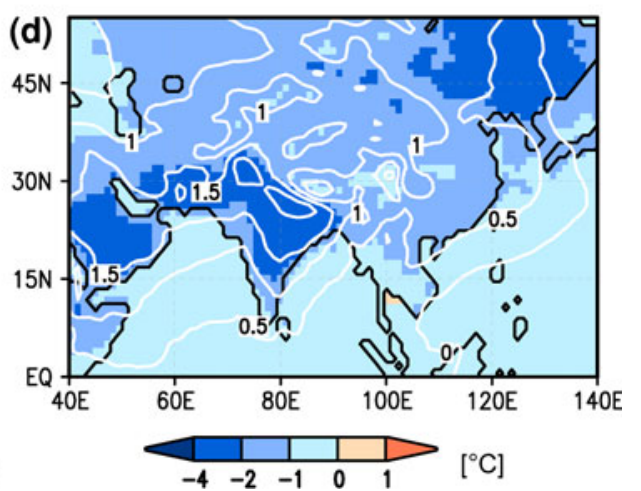

the monsoon season (only up to $6 \mathrm{~mm} /$ day) calculated in the present-day simulation. The amount of FMAM precipitation is strongly overestimated and the monsoon rainfall is underestimated by the model (cf. "Appendix"). Nevertheless, also in observations, the spring precipitation e.g. in the middle and lower reaches of the Yangtze River 
Fig. 10 Same as Fig. 8, but averaged over the present-day idealised monsoon season (June-September); a uppertropospheric zonal wind in $200 \mathrm{hPa}(\mathrm{m} / \mathrm{s})$; b vertical velocity in $400 \mathrm{hPa}(-0.01$ $\mathrm{Pa} / \mathrm{s})$; c vertically integrated moisture flux [vector, $(\mathrm{kg} / \mathrm{ms})$ ] and its convergence [shaded, $\left.\left(10 \times 10^{-5} \mathrm{~kg} / \mathrm{m}^{2} \mathrm{~s}\right)\right]$; d near surface air temperature [shaded, $\left.\left({ }^{\circ} \mathrm{C}\right)\right]$ and mean sea level pressure [contours, $(\mathrm{hPa})]$

Fig. 11 Same as Fig. 8, but difference between midHolocene and present-day, averaged over the idealised monsoon season (JuneSeptember); a uppertropospheric zonal wind in $200 \mathrm{hPa}(\mathrm{m} / \mathrm{s})$; b vertical velocity in $400 \mathrm{hPa}(-0.01$ $\mathrm{Pa} / \mathrm{s})$; c vertically integrated moisture flux [vector, $(\mathrm{kg} / \mathrm{ms})$ ] and its convergence [shaded, $\left.\left(10 \times 10^{-5} \mathrm{~kg} / \mathrm{m}^{2} \mathrm{~s}\right)\right]$; d near surface air temperature [shaded, $\left.\left({ }^{\circ} \mathrm{C}\right)\right]$ and mean sea level pressure [contours, $(\mathrm{hPa})]$
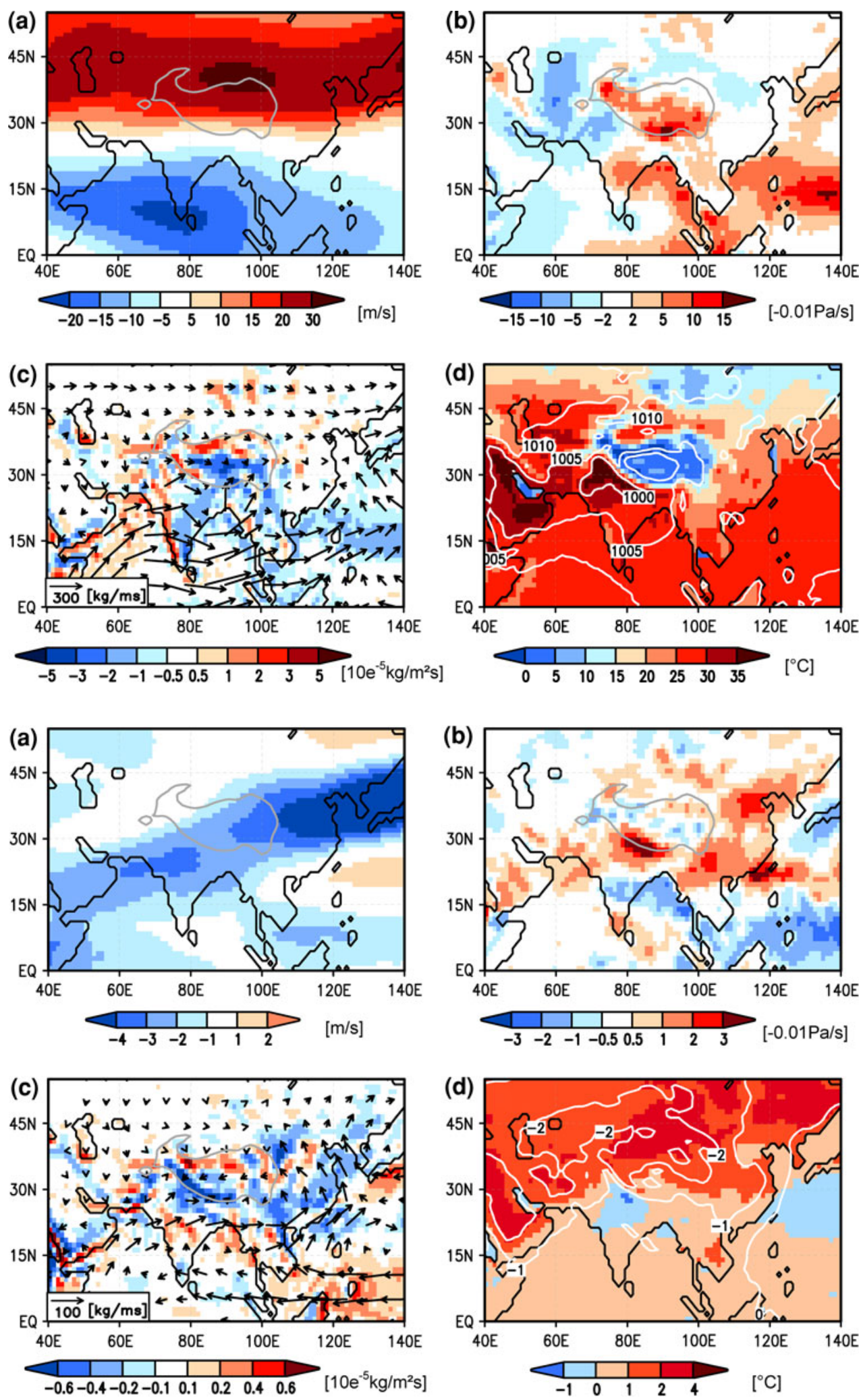

or in South China accounts for 32 and $35 \%$ of the annual total, respectively (Yihui and Zunya 2008). This premonsoon precipitation is mainly related to the mid-latitude baroclinic zone (Boo et al. 2011), i.e. it results from disturbances forming in the strong vertical-sheared westerly wind circulation. The interplay of the subtropical westerly jet and the Tibetan Plateau leads to subsidence in Northeast China and South Asia (Fig. 8a, b) and to the 
suppression of convective precipitation in these regions during the pre-monsoon season (Broccoli and Manabe 1992; Sato 2009). However, due to the upper-tropospheric wind divergence at the right entrance of the jet core, a zone of vertical ascent is established in Central and South China (Fig. 8b) favouring convective precipitation. In this region, the vertically integrated moisture-flux converges (Fig. 8c). The major circulation systems transporting moisture to this area are the southern branch of the middle- and uppertropospheric westerlies and a south-westerly circulation related to the West Pacific subtropical high. These moisture channels are also found in present-day observations (e.g. Yihui and Zunya 2008). The reduced incoming solar radiation on the Northern Hemisphere during mid-Holocene winter and early spring (cf. Fig. 1a) leads to a cooler climate and a higher mean sea level pressure over the continental Asian monsoon region compared to present-day (Fig. 9d). Above the adjacent ocean (particularly the Pacific), the temperature decrease in the lower atmosphere is less pronounced due to the larger heat capacity of the ocean compared to the land. The mean sea level pressure is similar as or even lower at mid-Holocene than at presentday (Fig. 9d). This leads to a north-easterly-wind anomaly in the lower troposphere in central-eastern and South China. In the upper troposphere, an anticyclonic circulation is established with a core at approx. $20^{\circ} \mathrm{N}, 100^{\circ} \mathrm{E}$ that leads to north-easterly winds south of $20^{\circ} \mathrm{N}$ (not shown). Both anomalies contribute to the decreased transport of moisture to Southeast Asia and the reduced moisture convergence in this area during mid-Holocene (Fig. 9c). Furthermore, the cooler lower and middle troposphere at mid-Holocene compared to present-day induces subsidence in Southeast Asia (Fig. 9b). Therefore, the pre-monsoonal (spring) precipitation is significantly reduced by up to $3.5 \mathrm{~mm} /$ day on the south-eastern Tibetan Plateau and more than $1 \mathrm{~mm} /$ day in Indochina as well as Central and South China at midHolocene (Fig. 7c).

\subsection{Mechanisms causing differences in the simulated summer precipitation}

The summer (JJAS) precipitation in South and East Asia is related to the Asian summer monsoon transporting moisture from the adjacent ocean to the continents (Fig. 10c, cf. e.g. Yihui and Zunya 2008). As a consequence of the increased insolation to the Northern Hemisphere during mid-Holocene and the different heat capacity of land and water, the Asian continent warms up more strongly than the oceans and the temperature and pressure gradients between the continent and adjacent ocean are enhanced (Fig. 11d). This leads to an intensification of the simulated Asian monsoon circulation and a strengthening of the moisture flux to the continent (Fig. 11c). The divergence of the simulated vertically integrated moisture flux shows a negative anomaly (more convergent) in North India, the southern Tibetan Plateau and South China, and a positive anomaly (more divergent) in Indochina and Central India between 6 and 0k. In large parts of the continental Asian monsoon domain, the vertical ascent in the mid-troposphere is enhanced at mid-Holocene (Fig. 11b). This is probably related to shifts in the upper-tropospheric wind circulation above the Asian continent being more divergent during mid-Holocene compared to present-day (not shown) and a weakening of the subtropical jet (Fig. 11a). The general heating of the lower and middle troposphere above the continent may also contribute to the enhanced uplift. The reduced mid-tropospheric vertical motion in Central India, Indochina and the western Pacific in the same latitude is probably owing to a northward shift of the Intertropical Convergence Zone that also has been suggested in previous studies (e.g. Braconnot et al. 2007b). The decreased moisture flux convergence and vertical uplift in Middle India, the Bay of Bengal and Indochina (Fig. 11b, c) leads to a reduction of summertime precipitation by up to $3 \mathrm{~mm} /$ day (Fig. 7). In these regions, the monsoon season is shortened (cf. Sect. 3.2). In contrast, the enhanced moisture transport and moisture flux convergence combined with the enhanced vertical uplift lead to an increased summertime precipitation in the rest of the Asian monsoon domain during mid-Holocene. Precipitation is increased by $3 \mathrm{~mm} /$ day in South China, up to $2.5 \mathrm{~mm}$ /day in Northeast China, up to $1.5 \mathrm{~mm} /$ day in North India and more than $5 \mathrm{~mm} /$ day at the Himalaya.

\subsection{Implications for the moisture reconstructions}

The appearance of several modes in the simulated precipitation signal reveals that the change in moisture/precipitation can not solely be attributed to summer monsoon dynamics. Other seasons, particularly the pre-monsoon (spring) season, have also to be taken into account. The individual sub-regions of the Asian monsoon domain respond differently to the Holocene insolation change in the model. Furthermore, the two monsoon systems reveal differences in the seasonal precipitation distribution. Figure $12 \mathrm{a}$ shows the ratio of present-day summer to spring precipitation and points out the difference between the Indian monsoon domain and the East Asian monsoon domain. India and the south-central Tibetan Plateau (mode II, Indian monsoon influenced regions) are strongly characterised by summer precipitation. The strengthening/ weakening of the Indian summer monsoon in the midHolocene simulation, thus, determines the annual total precipitation change in the model. This distinct signal can probably be represented easily in model and reconstructions. In contrast, the core region of the East Asian 

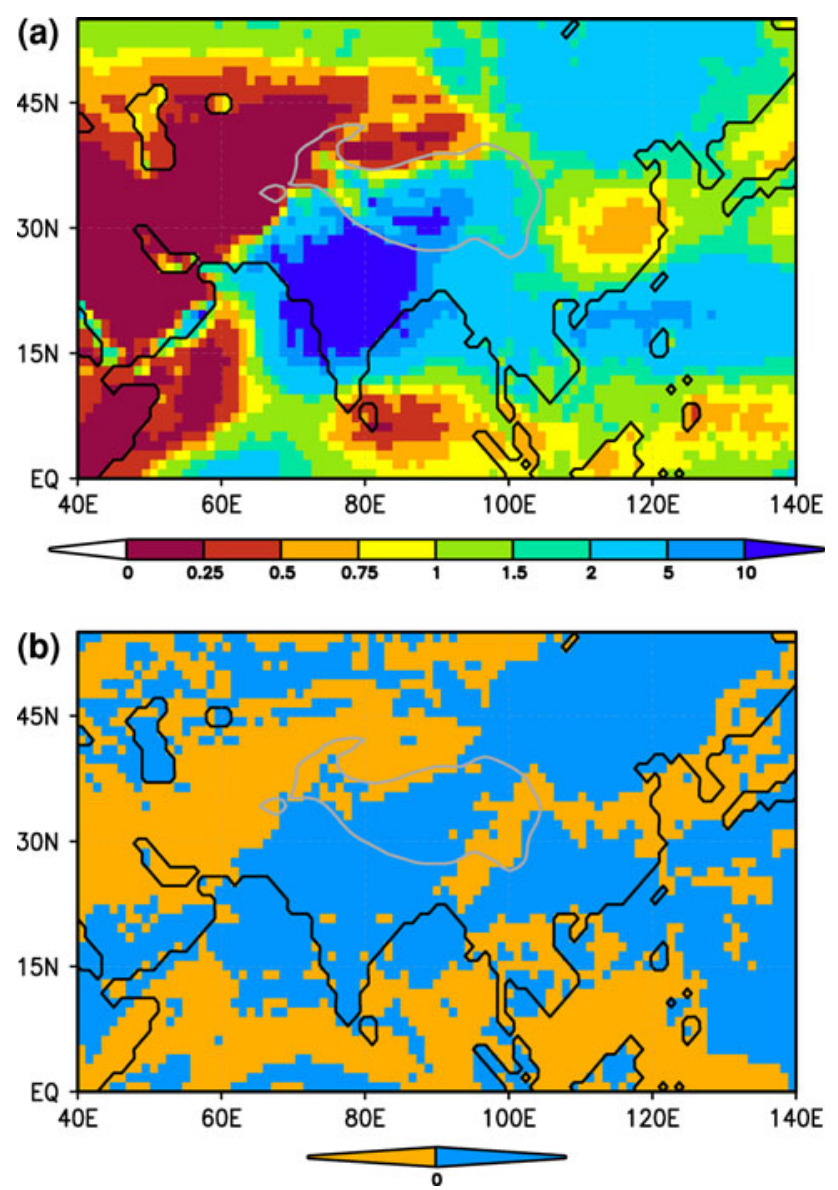

Fig. 12 a Ratio of summer (JJAS) to spring precipitation (FMAM) according to the present-day simulation and $\mathbf{b}$ change of the difference of summer and spring precipitation between mid-Holocene and present-day, red negative (i.e. decrease in FMAS $>$ increase in JJAS); blue positive. Please notice the similarity to Fig. 3

monsoon receives a large amount of precipitation outside the monsoon season. The difference in the simulated seasonal precipitation cycle between mid-Holocene and present-day is predominantly characterised by a reduction of precipitation in the months February to May (FMAM) and an increased precipitation during the months June to September (JJAS). The regions exhibiting this precipitation signal (mode I) are the regions in which the reconstructions show the patchiest moisture change and also the major disagreement to the model results. The model results, in turn, are less significant and characterised by a high variability. At least in the model, the sign of the annual mean precipitation change in these regions depends on the balance of the precipitation decrease in the pre-monsoon season and the precipitation increase in the monsoon season (cf. Fig. 12b). This ratio is probably not only determined by changes in the large- and regional-scale atmospheric dynamics between mid-Holocene and presentday, but also strongly affected by the local environment, particularly the local orography. The region with the strongest disagreement between the model and the reconstructions $\left(100-110^{\circ} \mathrm{E}, 30-40^{\circ} \mathrm{N}\right)$ is located at the eastern slopes and foothills of the Tibetan Plateau and the adjacent regions of the Loess Plateau where altitudes vary on a small spatial scale. Thus, the patchiness of the moisture reconstruction may to some extent be an imprint of the local topography that may lead to local climate differences and for example unevenly affects pollen records by upward pollen transport (Kramer et al. 2010).

\subsection{Comparison with other climate modelling simulations}

The model used in this study does not include a dynamically coupled ocean model. Therefore, important feedback mechanisms between ocean and atmosphere (e.g. sea-ice albedo feedback, or feedbacks within the water cycle) are neglected that may have an influence on the simulated climate change. The advantage of this model setup, however, is the possibility to conduct simulations at high numerical resolution (T106L31) without spending excessive computational power and time. We expect the simulated climate response to be more manifold in high resolution simulations. To assess the robustness of our results and conclusions, we compare the reconstructed moisture index with results from coarse-resolution simulations (Fig. 13) conducted with the comprehensive Earth system model ECHAM5/JSBACH-MPIOM (referred to as T31 $1_{\mathrm{AOV}}$, Dallmeyer et al. 2010) and performed within the Paleoclimate Modelling Intercomparison Project Phase II (PMIP2, Braconnot et al. 2007a, b). We only considered simulations conducted in fully coupled atmosphere-oceanvegetation models. The individual simulations are listed in Table 1. They have all been undertaken using similar boundary conditions and the same orbital forcing as in $A V_{6 k}$ and $A V_{0 k}$. For a detailed discussion on how the East Asian summer climate during the Holocene is represented in further simulations performed within PMIP2, we refer to Wang et al. (2010a).

Compared to the high resolution simulation, $\mathrm{T} 31_{\mathrm{AOV}}$ shows a much clearer annual precipitation change in the Asian monsoon domain with drier mid-Holocene conditions in central-eastern and South China and a wetter climate elsewhere (Fig. 13a). This uniform precipitation signal cannot represent the complex signal seen in reconstructions and points out the added value of the high resolution in $\mathrm{AV}_{6 \mathrm{k}}$ and $\mathrm{AV}_{\text {Ok. }}$. In the coarse resolution, the model is probably able to capture the large-scale response of the climate to the insolation forcing, but cannot represent the regional dynamics.

The individual model simulations of PMIP2 reveal large discrepancy regarding the sign, magnitude and pattern of 
Fig. 13 Same as Fig. 3, but for a the simulation $\mathrm{T} 31_{\mathrm{AOV}}$ (ECHAM5/JSBACH-MPIOM) and $\mathbf{b}-\mathbf{f}$ different simulations conducted within the PMIP2 project (Braconnot et al. 2007a, b), i.e. b MRI-CGCM2.3.4fa, c MRI-CGCM2.3.4nfa, d ECBILT-CLIO-VECODE, e FOAM-LPJ, f UBRISHadCM3M2
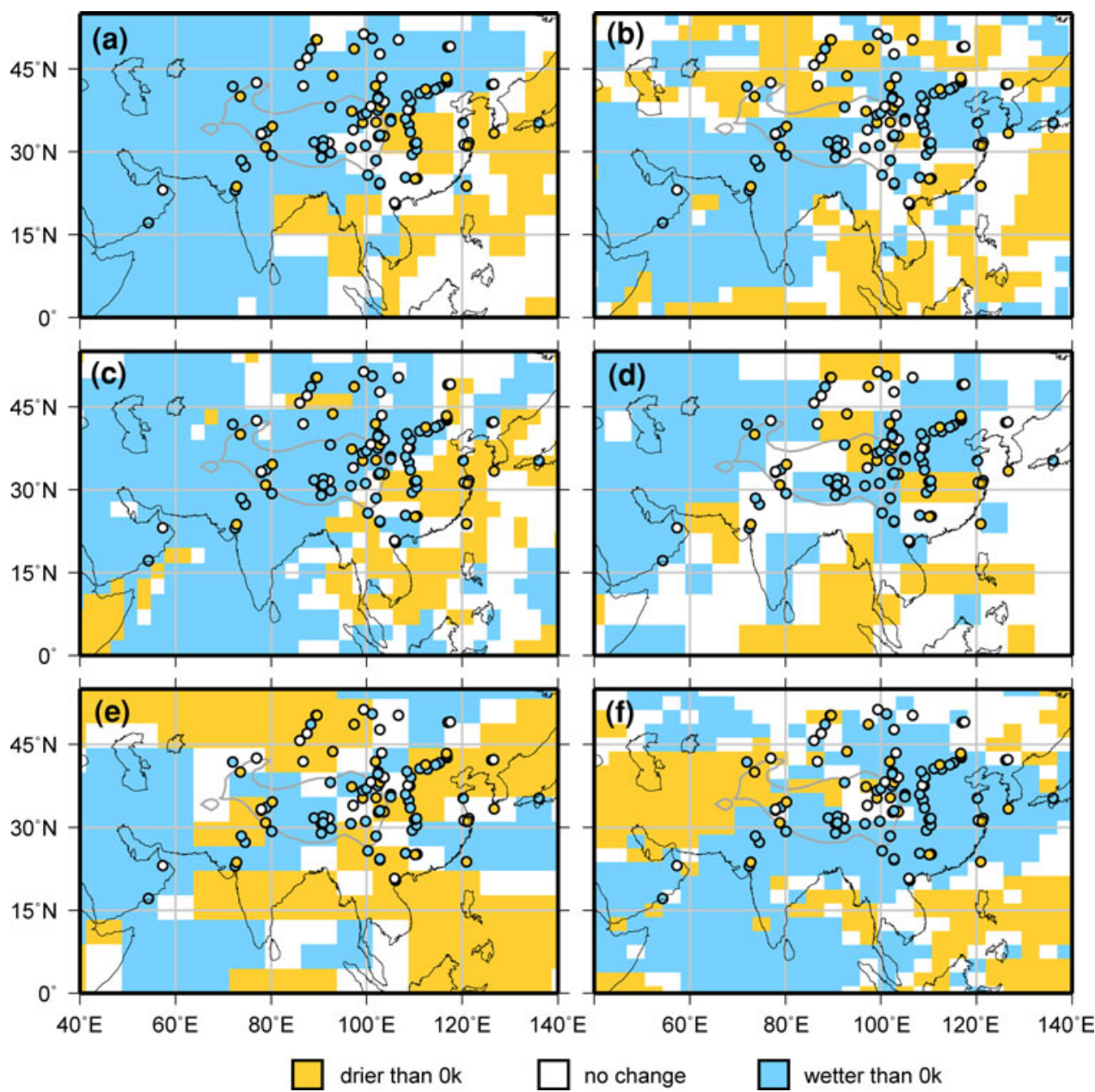

the $6 \mathrm{k}$ to $0 \mathrm{k}$ annual total precipitation change. Relatively robust signals are (Fig. 13b-f):

- the wetter mid-Holocene climate in Northern India (3 out of 5 models). The other two models [FOAM-LPJ (Fig. 13e) and ECBILT-CLIO-VECODE (Fig. 13d)] also show regions with drier or similar climate in midHolocene compared to present-day.

- the increased precipitation on the central southern Tibetan Plateau (around $90^{\circ} \mathrm{E}, 30^{\circ} \mathrm{N}$ ), this is shown by all 5 models.

Table 1 Overview on the PMIP2 simulations including an atmosphere, ocean and dynamic vegetation model

\begin{tabular}{ll}
\hline Model & Resolution \\
\hline MRI CGCM2.3.4nfa & T42L30 \\
MRI CGCM2.3.4fa & T42L30 \\
ECBILT CLIO VECODE & T21L3 \\
FOAM-LPJ & R15L18 \\
UBRIS HADCM3 & $2.5^{\circ} \times 3.75^{\circ}, \mathrm{L} 19$
\end{tabular}

For further information see: http://pmip2.1sce.ipsl.fr/
- the existence of regions in eastern China receiving less precipitation during mid-Holocene; only UBRIS-HADCM3M2 (Fig. 13f) suggests increased precipitation in the entire eastern China.

- the wetter climate in Northeast China (ca. $110-120^{\circ} \mathrm{E}$, $38-42^{\circ} \mathrm{N}, 3$ out of 5 models)

Figure 14 shows the difference in the seasonal precipitation cycle between mid-Holocene and present-day climate as simulated in $\mathrm{T} 31_{\mathrm{AOV}}$ and within PMIP2 for the area CE China and N India (cf. Fig. 6, area 2 and 7). These simulations confirm the different character of the East Asian and the Indian monsoon region and the different response of the monsoon systems to the insolation forcing. In all models except ECBILT-CLIO-VECODE, the seasonal signal referred to as mode I in our study, i.e. decreased precipitation in mid-Holocene spring and increased precipitation in mid-Holocene summer, can be found in central eastern China. In this region, UBRIS-HADCM3M2 and MRICGCM2.3.4fa (cf. Fig. 13f, b) show wetter conditions during mid-Holocene that can be related to a stronger increase of precipitation in summer overcompensating the decrease of precipitation in spring. The drier mid-Holocene 


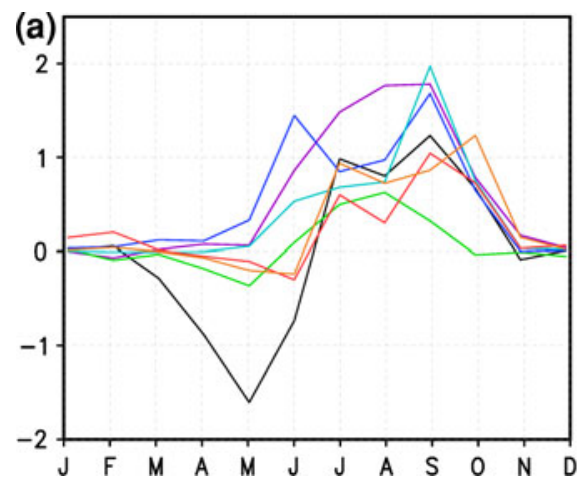

Fig. 14 Differences in the seasonal precipitation cycle between midHolocene and present-day (mm/day) for the regions a $\mathrm{N}$ India and b CE China (cf. Fig. 6), simulated within PMIP2 and in the two

climate simulated by MRI-CGCM2.3.4nfa and ECHAM5/ JSBACH-MPIOM (cf. Fig. 13c, a) is associated with strongly decreased precipitation during mid-Holocene spring that overcompensates the increased precipitation during summer. The other models show partly drier, partly wetter conditions in CE China.

In northern India, nearly all models simulate the seasonal signal referred to as mode II in our study, showing a strong increased precipitation during mid-Holocene summer and no response in the other seasons (Fig. 14a). FOAM-LPJ and to a minor extent ECBILT-CLIO-VECODE simulated decreased spring precipitation also for northern India during the mid-Holocene compared to present-day.

Overall, the simulated differences between the high resolution simulation $\mathrm{AV}_{6 \mathrm{k}}$ and $\mathrm{AV}_{0 \mathrm{k}}$ match the reconstructed moisture change better than the coarse resolution simulation in the same model $\left(\mathrm{T} 31_{\mathrm{AOV}}\right)$ despite of the

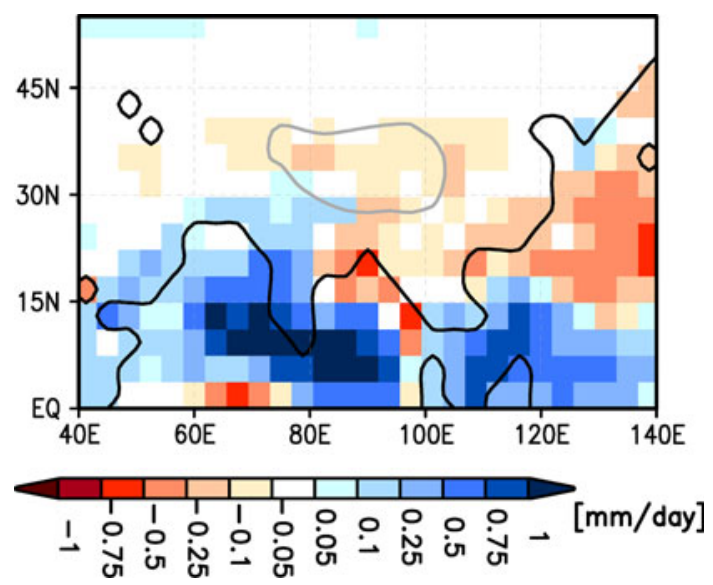

Fig. 15 Pure contribution of the atmosphere-ocean interaction to the mid-Holocene to present-day annual precipitation change $(\mathrm{mm} / \mathrm{day})$ as simulated by the coupled atmosphere-ocean-vegetation model ECHAM5/JSBACH-MPIOM (for details see Dallmeyer et al. 2010). The grey line marks the Tibetan Plateau

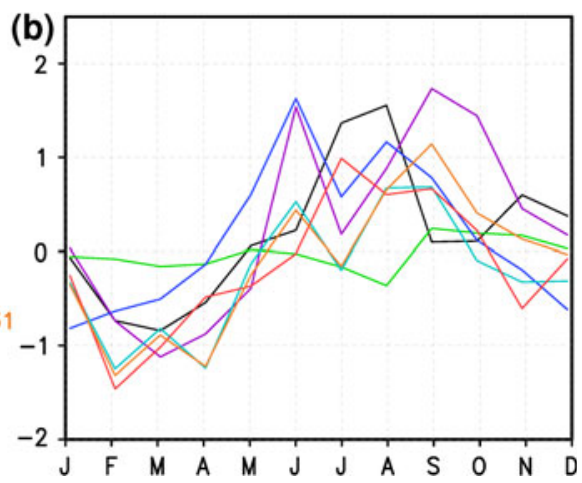

ECHAM5-JSBACH configurations (coarse resolution and coupled ocean vs. high resolution). Please notice, that this figure is based on monthly mean precipitation and not on pentad mean rainfall

missing ocean-atmosphere interactions. In the high resolution simulation, the number of points where the model results agree with the reconstructed moisture signal is increased by $30 \%$ compared to the low resolution simulation and the heterogeneous pattern of moisture change is better represented. The pure contribution of the oceanatmosphere interaction to the annual precipitation signal derived from coupled atmosphere-ocean-vegetation simulations in ECHAM5/JSBACH-MPIOM (for details we refer to Dallmeyer et al. 2010) is illustrated in Fig. 15. The interactive ocean enhances precipitation in India and reduces precipitation in the other parts of the continental Asian monsoon domain so that the precipitation signal simulated in $\mathrm{AV}_{6 \mathrm{k}}$ and $\mathrm{AV}_{0 \mathrm{k}}$ is amplified in most regions. Therefore, including a dynamic ocean model would probably neither improve nor worsen the reproducibility of the reconstructed precipitation change in our simulations.

\section{Summary and conclusion}

A high resolution numerical experiment conducted with the general circulation model ECHAM5/JSBACH by applying mid-Holocene insolation forcing has been compared to synchronised moisture reconstructions for the Asian monsoon region. Overall the model results and the reconstructions are in good agreement. They both show wetter conditions in large parts of the Indian monsoon region and a partly drier and partly wetter climate in East Asia. Especially in central-eastern China, reconstructions suggest a very inhomogeneous mid-Holocene to present-day annual total precipitation signal which indicates the complexity of the Asian monsoon dynamics. The model is able to capture this patchy signal and attributes the inhomogeneity to the different responses of the East Asian and Indian monsoon system to the insolation forcing. The East Asian monsoon is determined by a zonal pressure gradient, the Indian monsoon depends on a meridional pressure gradient. 
Therefore, the zonally uniform insolation change has different effects on these two monsoon sub-systems. Large parts of the Indian monsoon region receive most of the annual total precipitation during the summer monsoon season. In these regions, the difference in simulated annual rainfall between mid-Holocene and present-day can be attributed to changes in the summer monsoon season length and in the monsoon related precipitation, i.e. a prolongation and intensification of the summer monsoon in North India and a shortening and weakening of the summer monsoon in Bangladesh and Indochina. In large parts of Eastern China, present-day precipitation is not confined to the summer monsoon season, but also falls during spring. Therefore, the Holocene moisture change also depends on the response of the spring precipitation to the seasonal insolation forcing and, hence, on changes in the mid-latitude westerly wind circulation. The sign of the simulated annual total precipitation difference between mid-Holocene and present-day is determined by the balance of decreasing spring and increasing summer monsoon precipitation as response to the mid-Holocene insolation forcing. This may also explain the inhomogeneity in the reconstructions, since the ratio of spring to summer precipitation change could be less affected by the large-scale circulation but rather be sensitive to the local environment such as the orography that is very complex in the Asian monsoon region.

The coupled atmosphere-ocean-vegetation model simulations performed within the Paleoclimate Modelling Intercomparison Project Phase II (PMIP2) show large discrepancies among each other and have difficulties to capture the complexity of the reconstructed moisture signal. They cannot represent the inhomogeneity of the signal which might be a problem of the numerical resolution used in the PMIP2 simulations. Using coarse spatial resolutions, the models can probably simulate the large-scale response of the monsoon system to the insolation forcing, but not resolve the regional response. The conclusion that the sign of the annual total precipitation change depends on the balance of the spring and summer signals is confirmed by the PMIP2 simulations.

This study reveals the added value of using high numerical resolutions in climate modelling studies of the Asian monsoon system. It furthermore shows the importance of extending the analysis period of monsoon climate change to other seasons and points out the fact that paleoclimate moisture reconstructions cannot simply be interpreted as indicator for the summer monsoon strength and monsoon related precipitation. The variations in the Earth's orbit lead to changes in the seasonal insolation distribution and hence affect the rainfall in all seasons. The relevance of the non-monsoon seasons for the annual total precipitation might change with time. Therefore, paleoclimate moisture reconstructions in the Asian monsoon region should not simply be correlated and explained with variations in summer insolation.

Acknowledgments We acknowledge the international modeling groups participating in PMIP2 for providing their data for analysis and the Laboratoire des Sciences du Climat et de l'Environnement (LSCE) for collecting and archiving the model data. The PMIP2 Data Archive is supported by CEA, CNRS and the Programme National d'Etude de la Dynamique du Climat (PNEDC). The analyses were performed using the final version of the database. More information is available on http://pmip2.1sce.ipsl.fr/. We would like to thank T. Crueger, MPI-M, for constructive discussion and two anonymous reviewers for the helpful comments that improved our manuscript. This research is part of the priority program INTERDYNAMIK funded by the German Research Foundation (DFG). The high resolution climate model simulations have been performed at the German Climate Computing Center (DKRZ) in Hamburg, Germany.

Open Access This article is distributed under the terms of the Creative Commons Attribution License which permits any use, distribution, and reproduction in any medium, provided the original author(s) and the source are credited.

\section{Appendix: Simulated present-day precipitation pattern}

Figure 16 shows the annual mean precipitation of the simulation $\mathrm{AV}_{0 \mathrm{k}}$ compared to the observed climatology derived by the Global Precipitation Climatology Project (GPCP, version 2.1, 1979-2006, Adler et al. 2003) and the Climate Prediction Centre (CMAP, 1979-2008, Xie and Arkin 1997). Overall, the model captures the major annual precipitation pattern. The contrast between the arid/semiarid regions of central Asia and the wet monsoon region is well represented. The highest precipitation rates are simulated in the equatorial region at the Maritime Continent, the Bay of Bengal, in the Intertropical Convergence Zone and in the Subtropical Front which is related to the strong moisture convergence in the northern flank of the Western Pacific Subtropical High. However, the magnitude of the simulated and observed annual mean precipitation rates differ. The comparison exhibits strong rainfall deficits in large parts of the southern and western Asian continent. The simulated annual mean precipitation is underestimated by up to $750 \mathrm{~mm} /$ year in India and $1,400 \mathrm{~mm} /$ year in Indochina compared to GPCP. In contrast, the model overestimates the annual precipitation on the southern Himalaya by up to $4,500 \mathrm{~mm} / \mathrm{year}$. This could be related to an inappropriate parameterisation of convective precipitation at steep mountain slopes (Cui et al. 2006). Regarding precipitation over the ocean, the two observational datasets do not agree. The major difference of the $\mathrm{AV}_{0 \mathrm{k}}$ to both datasets is a poleward shift of the Pacific Intertropical Convergence Zone which is accompanied by a strong rainfall deficit in a ten degrees of latitude wide region 

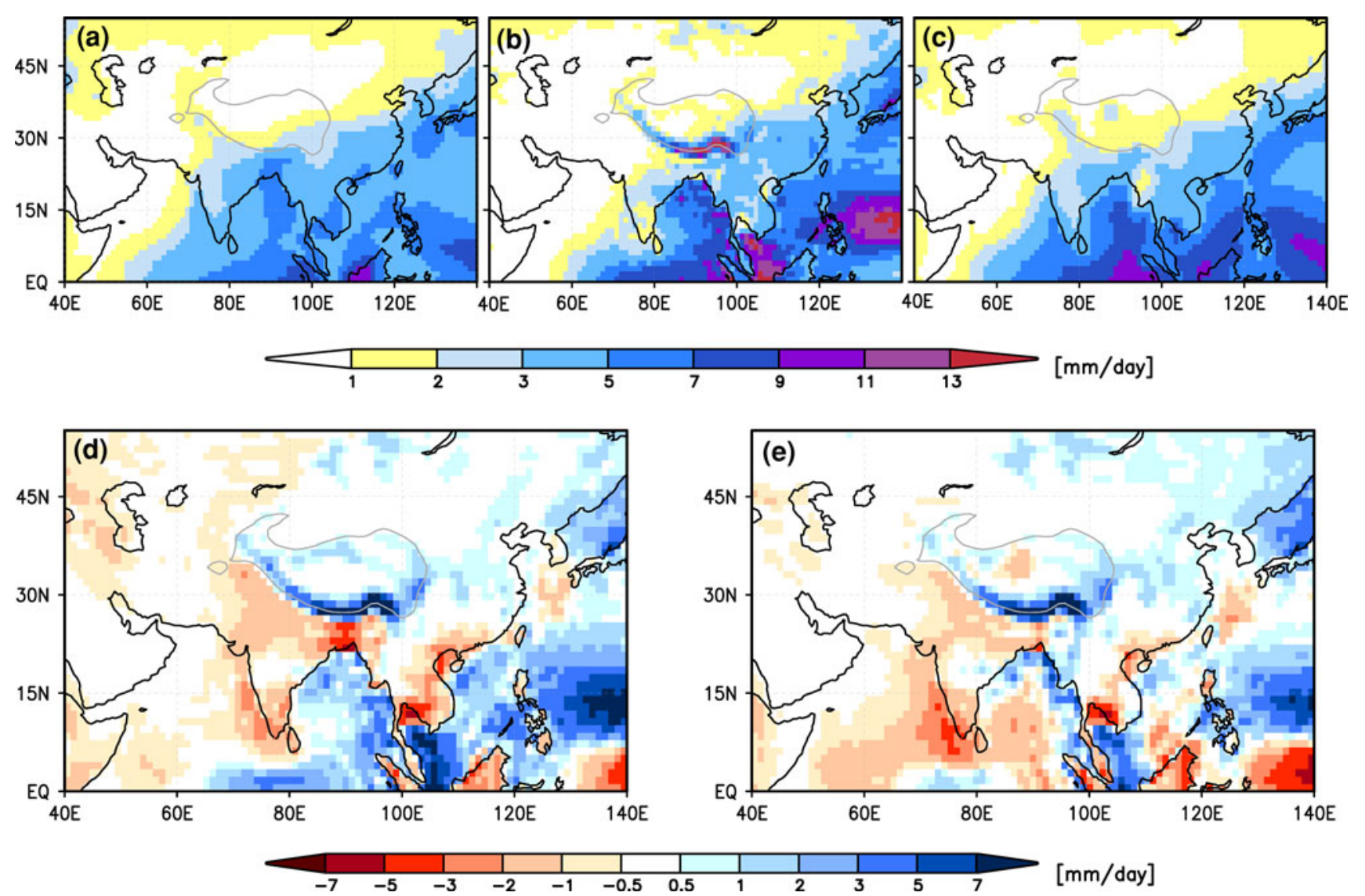

Fig. 16 Annual mean precipitation (mm/year) according to a the observational dataset GPCP (Adler et al. 2003); b the control simulation $\mathrm{AV}_{0 \mathrm{k}}$ (present-day orbit, pre-industrial $\mathrm{CO}_{2}$-concentration) and c the observational dataset CMAP (Xie and Arkin 1997); d difference $\mathrm{AV}_{0 \mathrm{k}}-\mathrm{GPCP}$; e difference $\mathrm{AV}_{0 \mathrm{k}}-\mathrm{CMAP}$. The grey line marks the Tibetan Plateau along the equator and an overestimation of the precipitation around $15^{\circ} \mathrm{N}$. Furthermore, the simulated annual mean precipitation rate exceeds the observed values in the oceanic part of the Maritime Continent by up to 3,000 $\mathrm{mm} /$ year. The precipitation rate in the northern Indian Ocean is underestimated by the model (up to $900 \mathrm{~mm} /$ year).

Figure 17 shows a latitude-time transect through the East Asian monsoon region $\left(110-120^{\circ} \mathrm{E}\right)$ and the Indian monsoon region $\left(70-80^{\circ} \mathrm{E}\right)$ based on pentad-mean precipitation rates. Compared to CMAP (Fig. 17b), many features of the annual precipitation cycle in the East Asian sector are well represented in the model (Fig. 17d). This includes, for instance, the simulation of spring precipitation at ca. $30^{\circ} \mathrm{N}$ and the seasonal March of the East Asian monsoon rainband, i.e. its northward jump in late spring and its slow retreat in autumn. The major difference in the simulated and observed cycle is the occurrence of a second rainband directly south of the equator that leads to a broadening of the rainband in the model. During the monsoon season, the model calculates too little precipitation (ca. 4-6 mm/day) in the central East Asian monsoon region which is associated with a $5^{\circ}$-northward displacement of the major monsoon front. The simulated spring precipitation period in eastern China starts too early and the rainband is located too far in the north $\left(\mathrm{ca} .4^{\circ}\right)$. In addition, the magnitude of spring precipitation is overestimated by the model. The weird looking line at $3^{\circ} \mathrm{S}$ in Fig. $17 \mathrm{~d}$, $\mathrm{f}$ is related to rainfall deficit at the south coast of Borneo.

The comparison of the Indian transects exhibits a strong rainfall deficit in the monsoon region nearly all over the year (Fig. 17a, c, e). Particularly in the summer season, the mean pentad rainfall rate in the model is too small by up to $6 \mathrm{~mm} / \mathrm{day}$. The general march of the Indian monsoon is well represented by the model, but the northward advance of the major rainband begins nearly 1 month too late.

The simulated differences in precipitation between midHolocene and present-day (cf. Sect. 3.1) are smaller than the differences between the simulated present-day climate and the observations. Since the systematic model biases (e.g. biases related to parameterisations) are probably similar in the mid-Holocene and present-day simulations, this fact does not affect the general credibility of the 
Fig. 17 Hovmöller diagram of the seasonal precipitation cycle in an Indian monsoon sector $\left(70-80^{\circ} \mathrm{E}\right.$, left panel) and an East Asian monsoon sector (110- $120^{\circ} \mathrm{E}$, right panel) for a-b the observational dataset CMAP (Xie and Arkin 1997); c-d the control simulation $\left(\mathrm{AV}_{0 \mathrm{k}}\right) ; \mathbf{e}-\mathbf{f}$ difference modelCMAP. Shown are pentad-mean precipitation rates ( $\mathrm{mm} / \mathrm{day})$.

The section separated by grey lines indicates the monsoon domain on the Asian continent, i.e. India and East China, respectively
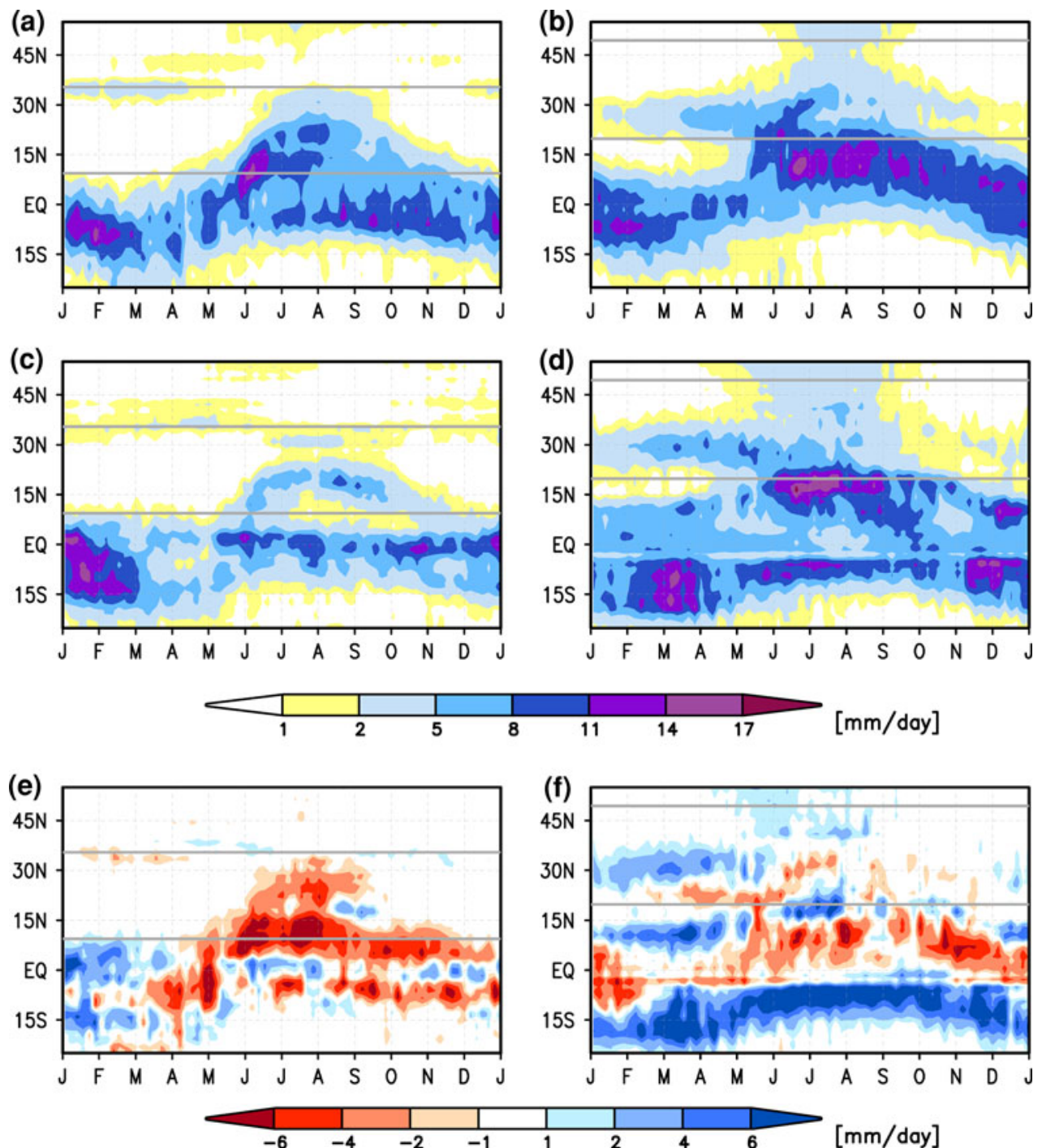

inferred results as long as only differences between the two time-slices are analysed.

\section{References}

Adler RF, Huffman GJ, Chang A, Ferraro R, Xie PP, Janowiak J, Rudolf B, Schneider U, Curtis S, Bolvin D, Gruber A, Susskind J, Arkin P, Nelkin E (2003) The version-2 global precipitation climatology project (GPCP) monthly precipitation analysis (1979-present). J Hydrometeor 4:1147-1167

An Z, Porter SC, Kutzbach JE, Wu X, Wang S, Liu X, Li X, Zhou W (2000) Asynchronous Holocene optimum of the East Asian monsoon. Quat Sci Rev 19:743-762

Berger A (1978) Long-term variations of daily insolation and Quaternary climate changes. J Atmos Sci 35(12):2362-2367

Boo KO, Martin G, Sellar A, Senior C, Byun YH (2011) Evaluating the East Asian monsoon simulation in climate models. J Geophys Res 116 (D01109). doi:10.1029/2010JD014737

Braconnot P, Otto-Bliesner B, Harrison S, Joussaume S, Peterchmitt JY, Abe-Ouchi A, Crucifix M, Driesschaert E, Fichefet T, Hewitt
CD, Kageyama M, Kitoh A, Laîné A, Loutre MF, Marti O, Merkel U, Ramstein G, Valdes P, Weber SL, Yu Y, Zhao Y (2007a) Results of PMIP2 coupled simulations of the midHolocene and last glacial maximum-part 1: experiments and large-scale features. Clim Past 3:261-277

Braconnot P, Otto-Bliesner B, Harrison S, Joussaume S, Peterchmitt JY, Abe-Ouchi A, Crucifix M, Driesschaert E, Fichefet T, Hewitt CD, Kageyama M, Kitoh A, Loutre MF, Marti O, Merkel U, Ramstein G, Valdes P, Weber SL, Yu Y, Zhao Y (2007b) Results of PMIP2 coupled simulations of the mid-Holocene and last glacial maximum-part 2: feedbacks with emphasis on the location of the ITCZ and mid- and high latitudes heat budget. Clim Past 3:279-296

Braconnot P, Marzin C, Grégoire L, Mosquet E, Marti O (2008) Monsoon response to changes in Earth's orbital parameters: comparisons between simulations of the Eemian and of the Holocene. Clim Past 4:281-294. doi:10.5194/cp-4-281-2008

Broccoli AJ, Manabe S (1992) The effects of orography on midlatitude northern hemisphere dry climates. J Clim 5:11811201

Brovkin V, Raddatz T, Reick CH, Claussen M, Gayler V (2009) Global biogeophysical interactions between forest and climate. Geophys Res Lett 36(L07405). doi:10.1029/2009GL037543 
Clift PD, Plumb RA (2008) The Asian monsoon: causes, history and effects. Cambridge Univ. Press, Cambridge

Cui X, Graf HF, Langmann B, Chen W, Huang R (2006) Climate impacts of anthropogenic land use changes on the Tibetan Plateau. Global Planet Change 54:33-56

Dallmeyer A, Claussen M, Otto J (2010) Contribution of oceanic and vegetation feedbacks to Holocene climate change in monsoonal Asia. Clim Past 6:195-218

Ding YH (2007) The variability of the Asian summer monsoon. J Meteor Soc Jpn 85:21-54

Ding YH, Chan JCL (2005) The East Asian summer monsoon: an overview. Meteorol Atmos Phys 89:117-142

Fischer N, Jungclaus JH (2011) Evolution of the seasonal temperature cycle in a transient Holocene simulation: orbital forcing and seaice. Clim Past 7:1139-1148

Fleitmann D, Burns SJ, Mudelsee M, Neff U, Kramers J, Mangini A, Matter A (2003) Holocene forcing of the Indian monsoon recorded in a stalagmite from Southern Oman. Science 300:1737-1739

Herzschuh U, Winter K, Wünnemann B, Li S (2006) A general cooling trend on the central Tibetan Plateau throughout the Holocene recorded by the Lake Zigetang pollen spectra. Quat Int 154-155:113-121

Joussaume S, Braconnot P (1997) Sensitivity of paleoclimate simulations results to season definitions. J Geophys Res 102(D2): 1943-1956

Kramer A, Herzschuh U, Mischke S, Zhang C (2010) Holocene treeline shifts and monsoon variability in the Hengduan Mountains (SE Tibetan Plateau), implications from palynological investigations. Palaeogeogr Palaeoclimatol Palaeoecol 286:23-41

Lau KM, Kim KM, Yang S (2000) Dynamical and boundary forcing characteristics of regional components of the Asian summer monsoon. J Clim 13:2461-2482

Li Y, Harrison S, Zhao P, Ju J (2009) Simulations of the impact of dynamic vegetation on interannual and interdecadal variability of Asian summer monsoon with modern and mid-Holocene orbital forcings. Global Planet Change 66(3/4):235-252

Maher BA (2008) Holocene variability of the East Asian summer monsoon from Chinese cave records: a re-assessment. Holocene 18(6):861-866

Maher BA, Hu M (2006) A high-resolution record of Holocene rainfall variations from the western Chinese Loess Plateau: antiphase behaviour of the African/Indian and East Asian summer monsoons. Holocene 16:309-319

Marsland SJ, Haak H, Jungclaus JH, Latif M, Roske F (2003) The Max-Planck-Institute global ocean/sea ice model with orthogonal curvilinear coordinates. Ocean Model 5:91-127

Marzin C, Braconnot P (2009) Variations of Indian and African monsoons induced by insolation changes at 6 and $9.5 \mathrm{kyr}$ BP. Clim Dyn 33(2-3):215-231

Prasad S, Enzel Y (2006) Holocene paleoclimates of India. Quat Res 66(3):442-453

Raddatz TJ, Reick CH, Knorr W, Kattge J, Roeckner E, Schnur R, Schnitzler KG, Wetzel P, Jungclaus J (2007) Will the tropical land biosphere dominate the climate-carbon cycle feedback during the twenty-first century? Clim Dyn 29:565-574

Roeckner E, Bäuml G, Bonaventura L, Brokopf R, Esch M, Giorgetta M, Hagemann S, Kirchner I, Kornblueh L, Manzini E, Rhodin A, Schlese U, Schultzweida U, Tompkins A (2003) The atmospheric general circulation model ECHAM5. Part I: model description. Max-Planck-Inst. f. Meteor. Report No. 349, Hamburg

Sato T (2009) Influences of subtropical jet and Tibetan Plateau on precipitation pattern in Asia: insights from regional climate modelling. Quatern Int 194:148-158

Wang B (ed) (2006) The Asian Monsoon. Springer/Praxis Publishing Co, Berlin

Wang B, LinHo (2002) Rainy season of the Asian-Pacific summer monsoon. J Clim 15:386-398

Wang B, Wu R, Lau KM (2001) Interannual variability of the Asian summer monsoon: contrasts between the Indian and the Western North Pacific-East Asian Monsoon. J Clim 14:4073-4090

Wang B, Clemens S, Liu P (2003) Contrasting the Indian and East Asian monsoons: implications on geologic timescales. Mar Geol 201(1-3):5-21

Wang YJ, Cheng H, Edwards RL, He YQ, Kong XG, An ZS, Wu JY, Kelly MJ, Dykoski CA, Li XD (2005) The Holocene Asian monsoon: links to solar changes and North Atlantic climate. Science 308:854-857

Wang T, Wang HJ, Jiang DB (2010a) Mid-Holocene East Asian summer climate as simulated by the PMIP2 models. Palaeogeogr Palaeoclimatol Palaeoecol 288:93-102

Wang YB, Liu XQ, Herzschuh U (2010b) Asynchronous evolution of the Indian and East Asian Summer Monsoon indicated by Holocene moisture patterns in monsoonal central Asia. Earth-Sci Rev 103(3-4):135-153. doi:10.1016/j.earscirev.2010.09.004

Webster PJ, Magaňa VO, Palmer TN, Shukla J, Tomas RA, Yanai M, Yasunari T (1998) Monsoons: processes, predictability, and the prospects for prediction. J Geophys Res 103(C7):14451-14510

Wei J, Wang H (2004) A possible role of solar radiation and ocean in the mid-Holocene East Asian monsoon Climate. Adv Atmos Sci 21(1):1-12

Wu GX, Liu YM, Wang TM, Wan R, Liu X, Li W, Wang Z, Zhang Q, Duan A, Liang X (2007) The influence of the mechanical and thermal forcing of the Tibetan plateau on the Asian climate. J Hydrometeorol 8:770-789

Xie P, Arkin PA (1997) Global precipitation: a 17-year monthly analysis based on gauge observations, satellite estimates, and numerical model outputs. Bull Amer Meteor Soc 78:2539-2558

Ye DZ, Wu GX (1998) The role of the heat source of the Tibetan Plateau in the general circulation. Meteorol Atmos Phys 67:181-198

Yihui D, Zunya W (2008) A study of rainy seasons in China. Meteorol Atmos Phys 100(1-4):121-138. doi:10.1007/s00703-008-0299-2

Zhou B, Zhao P (2010) Modeling variations of summer upper tropospheric temperature and associated climate over the Asian Pacific region during the mid-Holocene. J Geophys Res 115, D20109. doi:10.1029/2010JD014029 